IZA DP No. 6755

Explaining the Birth Order Effect: The Role of Prenatal and Early Childhood Investments

Jee-Yeon K. Lehmann

Ana Nuevo-Chiquero

Marian Vidal-Fernández

July 2012 


\title{
Explaining the Birth Order Effect: The Role of Prenatal and Early Childhood Investments
}

\author{
Jee-Yeon K. Lehmann \\ University of Houston \\ Ana Nuevo-Chiquero \\ IEB, Universitat de Barcelona
}

\author{
Marian Vidal-Fernández \\ University of New South Wales \\ and IZA
}
Discussion Paper No. 6755
July 2012

IZA
P.O. Box 7240
53072 Bonn
Germany

Phone: +49-228-3894-0

Fax: +49-228-3894-180

E-mail: iza@iza.org

\begin{abstract}
Any opinions expressed here are those of the author(s) and not those of IZA. Research published in this series may include views on policy, but the institute itself takes no institutional policy positions.

The Institute for the Study of Labor (IZA) in Bonn is a local and virtual international research center and a place of communication between science, politics and business. IZA is an independent nonprofit organization supported by Deutsche Post Foundation. The center is associated with the University of Bonn and offers a stimulating research environment through its international network, workshops and conferences, data service, project support, research visits and doctoral program. IZA engages in (i) original and internationally competitive research in all fields of labor economics, (ii) development of policy concepts, and (iii) dissemination of research results and concepts to the interested public.
\end{abstract}

IZA Discussion Papers often represent preliminary work and are circulated to encourage discussion. Citation of such a paper should account for its provisional character. A revised version may be available directly from the author. 


\section{ABSTRACT \\ Explaining the Birth Order Effect: The Role of Prenatal and Early Childhood Investments *}

The critical role of prenatal and early childhood conditions on adult outcomes has been the focus of a rich body of research. In this paper, we examine various pre- and postnatal investments as possible sources behind the "birth order effect" - significant differences in the educational and labor market outcomes across children of varying birth orders. Taking advantage of a rich set of information on in utero and early childhood conditions in the Children of the NLSY79, we find that, within the same household, siblings of higher birth order experience a lower reduction in cigarette usage during pregnancy, are breastfed less often, and experience less cognitive stimulation and emotional support at ages 0 to 1 . Next, we test for the presence of birth order effects in early cognitive and non-cognitive test scores and examine whether these differences can be explained by variations in prenatal and early childhood investments. Although there exists a significant negative relationship between birth order and early cognitive/non-cognitive test scores, the size and the significance of the negative birth order effects in test scores and educational attainment are robust to controlling for variations in early childhood factors.

JEL Classification: J10, J13, I24

Keywords: birth order, early test scores, parental investment, prenatal investment, postnatal investment, early childhood investment, fetal origins hypothesis, cognitive outcomes, non-cognitive outcomes

Corresponding author:

Marian Vidal-Fernández

School of Economics

Australian School of Business

University of New South Wales

Kensington, 2052, NSW

Australia

E-mail: m.vidal-fernandez@unsw.edu.au

\footnotetext{
* We are grateful to Andy Zuppann and Chinhui Juhn for their helpful comments and suggestions. Any remaining errors are our own.
} 


\section{Introduction}

The critical role of prenatal and early childhood conditions on child and adult outcomes has been the focus of a rich body of recent research. The literature provides increasing empirical support for the idea that in utero and early childhood investments can greatly shape a person's future educational and labor market outcomes. First, the "fetal origins" or the "fetal programming" hypothesis as proposed by Barker (1990) suggests that inadequate nutrition or exposure to harmful chemicals or conditions in utero "programs" the fetus to have persistent and latent metabolic or biological characteristics that can lead to future health problems and, in turn, worse educational and labor market outcomes. Reviews of the fetal origins literature by Gluckman and Hanson (2005), Heckman (2007), and Almond and Currie (2010) cite a number of key studies in medicine and economics that find fetal and maternal nutrition, birthweight, fetal exposure to toxins, alcohol, and smoking, and infant development in the first year are all significant predictors of adult health, educational, labor market outcomes. Second, a growing strand of economic research demonstrates that the child's first few years of development are especially critical determinants of adolescent and adult cognitive and noncognitive outcomes, which are predictive of educational attainment and earnings (Knudsen, Heckman, Cameron and Shonkoff 2006, Cunha and Heckman 2007, Heckman, Stixrud and Urzua 2006, Heckman and Masterov 2007).

Motivated by the strong evidence on the importance of in utero and early childhood conditions on later outcomes, we examine prenatal and early childhood environment as a possible explanation for the so-called "birth order effect" - significant differences in educational and labor market outcomes across children of varying birth order in observably similar households or among siblings within the same household. Although several studies have found a significantly negative relationship between birth order and educational attainment (Behrman and Taubman 1986, Booth and Kee 2009, Kantarevic and Mechoulan 2006), IQ (Black, Devereux and Salvanes 2007a), and adult earnings (Behrman and Taubman 1986, Kantarevic 
and Mechoulan 2006) $\sqrt{1}$, studies examining the possible causes of birth order effects have been quite limited. Price (2008) and Monfardini and See (2011) investigate the role of parental time investment and find that although parents do spend less quality time with children of higher birth order, the effect remains negative and significant even when controlling for parental time investment. Similarly, the negative relationship between IQ and birth order found in Black et al. (2007a) is robust to controlling for several birth endowments such as birthweight, gestation period, and head size.

In this paper, we take advantage of the rich data on prenatal and early childhood investments and conditions found in the Children of the National Longitudinal Survey of the Youth 1979 (CNLSY79) to first examine whether there are significant differences in important in utero, birth, and early childhood conditions across siblings, controlling for family fixed effects. We find that, within the same household, siblings of higher birth order experience a lower reduction in mother's cigarette usage during pregnancy and are breastfed less often. Furthermore, examining the child's home environment at ages 0 to 1, we find a large and significant negative relationship between birth order and measures of emotional and verbal responsiveness of the mother, maternal acceptance and involvement with the child, and the presence of material for learning and stimulation in the home. Having established that there are significant differences in cigarette usage, prenatal care, breastfeeding, and early home environment across children of different birth order in the same family, we next test for the presence of birth order effects in early cognitive and non-cognitive test scores to assess the evolution of birth order differences in educational outcomes and ask whether these differences can be explained by variations in prenatal and early childhood conditions. We find a strong negative relationship between increasing birth order and cognitive and non-cognitive test scores, with the achievement gap between the first-born and higher-order siblings increasing as the children reach adolescence. Birth order effects are most significant in the children's reading scores and measures of self-worth at the beginning of their teen years. However,

\footnotetext{
${ }^{1}$ The results on earnings, however, are not robust to controlling for observable childhood family background characteristics in (Behrman and Taubman 1986).
} 
despite our finding that there are significant differences in prenatal and early childhood conditions across children of different birth order, we find that the size and the significance of the negative birth order effects on cognitive/non-cognitive tests, as well as in educational attainment, are robust to controlling for these early childhood factors. These results suggest several possible interpretations. One, birth order effects on educational outcomes are not determined by biological differences or variations in early childhood environments; two, its effects are latent until later in adulthood; or three, common measures of prenatal and early childhood conditions fail to adequately capture critical differences in early health and home conditions within a family.

Our paper makes a number of key contributions to the birth order literature. First, to our knowledge, this paper is a first attempt to test whether there exists birth order effects across many types of early cognitive and non-cognitive test scores.2 Previous studies have largely focused on the relationship between birth order and adult educational attainment or earnings, yet we believe that assessing whether these differences in achievement are present even at early ages is important for unearthing the possible causes and dynamics of the birth order effect. Second, despite growing evidence of the importance of prenatal and early childhood investments in health and education as well as early home environments on children's adolescent and adult outcomes, no study has assessed whether these early childhood conditions other than parental time can help explain the relationship between birth order and children's later achievement. ${ }^{3}$ In this paper, we utilize the rich data on specific prenatal and early childhood health, educational, and emotional investments and conditions present in the Children of the NLSY79 data to study the impact of these potentially critical factors on explaining birth order effects. Finally, because of the richness and the longitudinal

\footnotetext{
${ }^{2}$ Heiland (2009) is the only study of which that we are aware that examines the relationship between birth order and an early cognitive test. However, he focuses on only the Peabody Picture Vocabulary Test (PPVT) scores and does not include other cognitive tests. We do not know of any study that investigates the presence of birth order effects on early non-cognitive outcomes.

${ }^{3}$ Booth and Kee (2009) may be considered an exception. However, their conclusion that latter-born children have lower shares of educational resources is not directly identified, and they are unable to pinpoint what types of resources higher birth-order children lack. Moreover, due to data limitations, they are unable to estimate a family fixed effects model.
} 
nature of our data, we are able to meet many of the strong requirements on data analysis that will lead to unbiased estimates of the birth order effect. ${ }^{4}$ We employ family fixed effects throughout our empirical estimations to avoid any potential biases that may arise from unobservables in cross-sectional analysis. Further, we include children's cohort indicators in our controls to account for any cohort specific effects on our variables of interest.

\section{Related Literature on Birth Order Effects}

There are a number of theories outlining the potential channels through which birth order effects might occur. First, parents may face different time and financial constraints over their lifetime that may prevent them from equalizing their resources and investments across children. On one hand, if there are time and resources constraints, first-born and last-born children may benefit from their greater share of resources compared to middle-born children (Birdsall 1991). However, if parents' earnings tend to increase over their life cycle, later-born children may face more advantages than their earlier-born siblings (Parish and Willis 1993). Second, changing composition or parental characteristics may contribute to differing home environments across children of different birth order. For example, later-born children may be more intellectually stimulated by growing up with older children and better educated parents (Zajonc 1976). Yet, if the level of intellectual stimulation at home is closely tied to parental time constraints, later-born children may be disadvantaged by being part of a larger family. Third, biological or physiological differences may also induce varying outcomes. Later-born children have older mothers, and older mothers are more likely to give birth to children of lower weight ${ }^{5}$ and experifnce greater number of complications during pregnancy and at birth. On the other hand, mothers may become better child caretakers as they gain experience with each child, and later-born children may benefit from better child rearing practices. Recently, more sophisticated optimal stopping models or endogenous fertility models have shown that

\footnotetext{
${ }^{4}$ See Blake (1989), Rodgers, Cleveland, van den Oord and Rowe (2000), Black, Devereux and Salvanes (2005), and Black et al. (2007a) for details on these requirements.

${ }^{5}$ However, first-born children may also be more likely to have lower birth weight.
} 
less than expected draw in the quality of the latest child may either demotivate parents from having additional children or to continue having children until they reach an optimal stopping quality (Ejrnæs and Pörtner 2004). The former effect would imply that earlier-born children will tend to have better outcomes while the latter implies that later-born children would be advantaged.

Despite the theoretical ambiguity in the sign of the relation between birth order and children's educational and labor market outcomes, most of the latest empirical studies on birth order effects have found a strong, monotonically decreasing relationship. Improving upon earlier studies suffering from estimation limitations due to small sample sizes and/or inability to control for family fixed effects and/or cohort effects (Behrman and Taubman 1986, Kessler 1991, Hanushek 1992, Iacovou 2001), Black et al. (2005) use detailed national administrative data from Norway and find a strong, negative relationship between the birth order and the child's education attainment and adult earnings within a family, and these birth order effects appear to be of similar magnitude across families of varying sizes. The significance of birth effect on education and earnings has been corroborated using the U.S. Panel Study of Income Dynamics (PSID) in Kantarevic and Mechoulan (2006) who estimate a family fixed effects model and find that first borns have higher education achievement, high school completion rates, and earnings. Similarly, Conley and Glauber (2006) employ the sibling-sex composition instrument used in Angrist and Evans (1998) in analyzing educational data from the 1990 5\%-sample of the Public Use Micro Sample (PUMS) and find that while the latter-born children in larger families are more likely to be held back in school, family size does not seem to affect the first-born. Heiland (2009) examines birth order effects on early verbal ability test scores using the Children of the NLSY79 and finds that compared to their middle-born siblings, first-born children have higher Peabody Picture Vocabulary Test (PPVT) scores.

In view of these strong findings on birth order effects in educational attainment and earnings, much of the latest research on birth effects have focused on empirically exploring 
the possible causes of the relationship. However, most of these studies have found that the birth order effect is robust to controlling for possible differences in birth endowments, parental time, and maternal quality time. Using the same Norway administrative dataset as in Black et al. (2005), Black, Devereux and Salvanes (2007b) find a significant effect of birth order on IQ with the earlier born children having higher IQs by about one-fifth of a standard deviation or approximately three IQ points ${ }^{6}$ Yet when controlling for birth endowments such as birthweight, gestational period, and head size, the estimated birth order effects remain significant, actually rising in their magnitudes.

Several studies have assessed the role of parental time variations across children of different birth order. Price (2008) uses data from the American Time Use Survey (ATUS) and finds that parents tend to spend equal time with each of their children at any given point in time, and the total parental time with children decreases with age, especially with the age of the oldest child. These patterns, in turn, translate into the first-born child receiving roughly 20 to 30 more minutes of quality time each day with a parent compared to a second-born child. Despite his strong findings on parental time differences across siblings in his data, Price (2008) is unable to assess whether differences in parental time is significantly correlated with children's education outcomes and whether birth order effects are robust to controlling for parental quality time. Monfardini and See (2011) directly address these two remaining questions in their examination of maternal quality time and birth order in the Child Development Supplement (CDS) of the PSID. In a household fixed effects model, they find a significant negative relationship between maternal quality time and birth order, yet the birth order effects on education remain negative and significant even controlling for these differences in maternal quality time. Moreover, estimates show that differences in maternal quality time are insignificant correlates of variations in children's education outcomes.

Finally, Booth and Kee (2009) ask whether variations in family resources other than parental time across children can explain the birth order effect. Using the British Household

\footnotetext{
${ }^{6}$ Black et al. (2007b) note that this IQ gap is of similar magnitude as the black-white gap in the U.S.
} 
Panel Survey, Booth and Kee show that the shares of the family educational resources are decreasing with birth order. Controlling for parental family income, parental age at both and family level attributes, they find that children from larger families and with higher birth order have lower educational attainment. In contrast to Black et al. (2005), the family size effect does not disappear when controlling for birth order. Nevertheless, due to data limitations, they cannot estimate a family fixed effects model, and therefore cannot control for non-time varying unobservable family characteristics that are correlated with household resources or fertility decisions.

Motivated by the existing evidence on the significance of in utero and early childhood environments on children's later outcomes.7 we explore prenatal and early childhood investments in health, education, and maternal emotion/verbal responsiveness during the child's first year as possible causes of birth order effects. We first investigate whether there are indeed significant differences in key prenatal and early childhood investments and home conditions across siblings of different birth order. Next, we examine birth order effects not merely in education attainment or adult earnings but in cognitive and non-cognitive test scores from early childhood and adolescence in an effort to disentangle the evolution of birth order effects from childhood to adulthood. Finally, we assess whether variations in prenatal and early childhood environments are able to explain differences in test scores and adult outcomes across children of different birth order.

The rest of the paper is organized as follows. Section 3 briefly describes the Children of the NLSY79 and summarizes our cognitive and non-cognitive assessments of interest. We also include detailed description of our measures of prenatal and postnatal inputs and early home environment. Section 4 outlines our empirical strategy and presents the results. Finally, Section 5 concludes and suggests avenues for future research.

\footnotetext{
${ }^{7}$ An extensive review of literature is outside the scope of this paper. See Gluckman and Hanson (2005), Heckman (2007), Almond and Currie (2010) for a detailed review of the fetal origins literature and Knudsen et al. (2006), Cunha and Heckman (2007), Heckman et al. (2006), and Heckman and Masterov (2007) for notable studies on the importance of the child's first few years of development.
} 


\section{Data}

We rely on data from the 1979 cohort of the National Longitudinal Survey of Youth (NLSY79). The NLSY79 is a nationally representative sample of 12,686 men and women between 14 and 21 years old who were first interviewed in 1979. Periodic surveys of these individuals have been conducted since then, collecting rich information on employment, income, welfare program participation, education, and other background variables.

Starting in 1986, 11,420 children of the 6,283 female NLSY79 respondents have been interviewed bi-annually forming the Children of the NLSY79 (CNLSY79) sample. The child survey includes information on prenatal investments, birth outcomes, early childhood parental investments and health, scores from cognitive and non-cognitive assessments, quality of the home environment, as well as additional demographic and development information collected from either the mother or the child. Some children born before or in 1972 never belonged to the CNLSY79, because once they turn 15 they leave the sample and start the NSLY79 Young Adults survey, which resembles the NLSY79 questionnaire. The CNLSY79 provides unique and detailed longitudinal information on a large nationally representative sample of mothers and their children. The availability of a thorough record of the mothers' employment records and their background characteristics along with extensive data on children's prenatal and early childhood health and cognitive/non-cognitive development indicators make the NLSY79 Children and Young Adults an ideal dataset to explore the relationship between birth order and child's cognitive and educational outcomes and its possible causes found in in utero and early childhood environments.

\subsection{Pre/Postnatal Inputs and Birth Outcomes}

As potential explanations for the birth order effects on child cognitive/non-cognitive test scores and adult education/earnings outcomes, we examine various measures of prenatal and postnatal maternal behavior and investments as well as several key child outcomes at birth 
Table 1: Summary statistics

\begin{tabular}{lrrr}
\hline \hline \multicolumn{1}{c}{ Variable } & Mean & Std. Dev. & $\mathrm{N}$ \\
\hline Prenatal Inputs: & & & \\
\# of alcohol drinks per week & 2.215 & 5.160 & 2468 \\
Reduction in alcohol use & 0.887 & 0.316 & 2468 \\
\# of cigarettes per day & 3.556 & 5.256 & 1790 \\
Reduction in smoking & 0.767 & 0.423 & 1790 \\
Delayed prenatal care (first visit > 4 months) & 0.163 & 0.370 & 5254 \\
Month of first prenatal care (if not delayed) & 1.921 & 0.708 & 4298 \\
& & & \\
Birth Outcomes: & & & \\
Gestational length (weeks) & 38.680 & 2.139 & 5254 \\
Birth weight (ounces) & 118.764 & 21.376 & 5254 \\
Length at birth (inches) & 20.135 & 1.617 & 5254 \\
Premature (weeks < 37) & 0.207 & 0.405 & 5254 \\
Low birth weight (bw < 88 oz) & 0.071 & 0.256 & 5254 \\
Overweight at birth (bw > 142 oz) & 0.122 & 0.327 & 5254 \\
& & & \\
Postnatal Investments: & & & \\
Ever breastfed & 0.534 & 0.499 & 5254 \\
Weeks breastfed if at all & 20.692 & 20.946 & 2448 \\
HOME Score at Age 0 to 1 (Total) & 140.150 & 23.305 & 2494 \\
HOME Score at Age 0 to 1 (Cognitive) & 65.897 & 15.871 & 2417 \\
HOME Score at Age 0 to 1 (Emotional) & 74.857 & 12.703 & 2255 \\
\hline \hline
\end{tabular}

Notes: Weighted means. All alcohol and cigarette consumption variables are conditional on the mother having had smoked or consumed alcohol 12 months before giving birth. The sample is restricted to mothers/children with non-missing prenatal input, birth outcomes, breastfeeding, employment status, and welfare information.

that have been shown to be important determinants of child/adult health and development in medical and health economics literature. Specifically, we investigate the role of (i) alcohol and smoking use and reduction during pregnancy, patterns of prenatal medical visits, (ii) gestational length, prematurity, birth weight/length, (iii) breastfeeding patterns in the child's first year, and (iv) home environment during the child's first year of life.

Table 1 reports the summary statistics of these pre/postnatal investment and birth outcome variables. Despite the evidence that alcohol and cigarette consumption during pregnancy are linked to increased rates of birth complications, defects, and development problems (CDC 2001, CDC 2004, Almond and Currie 2010), conditional on having had used alcohol 
or cigarettes before pregnancy, $]^{8}$ the mothers in the CNLSY79 still consume on average 2.2 drinks per week and 3.6 cigarettes per day while pregnant. However, the vast majority of the women do report that they did reduce alcohol and cigarette use during pregnancy. Only about $16 \%$ of the women significantly delayed receiving prenatal care, having her first doctor's visit on the 4th month of pregnancy or later. For those who did not delay receiving prenatal care, the first visit typically occurs during the second month of pregnancy.

The middle panel of Table 1 presents the means of birth outcomes. A typical child in our sample is born around the 38th week of gestation, weighs approximately 120 ounces (or 7.5 pounds), and measures 20 inches at birth. Although the proportion of children born with a low birth weight is only around $7 \%$, it is notable that the proportion of those born overweight is almost twice as large. About $20 \%$ of the children in our sample are born prematurely, being born before the 37th week of gestation.

Despite American Academy of Pediatrics' (AAP) recommendation that infants should be exclusively breastfed during his/her first six months in light of the potential health benefits associated with breastfeeding (Belfield and Kelly 2010), the bottom panel of Table 1 shows that only half of the children in our sample are ever breastfed. For those children the mothers choose to breastfeed, the average duration is around 20 weeks, about one month less than the AAP's recommendation.

Finally, taking advantage of information on the children's home environment in the CNLSY79, we explore the role of early home environment and parental interaction as a potential explanation for birth order effects. We rely on the Home Observation Measurement of the Environment (HOME) measure in the CNLSY79 that has been used by researchers to understand the quality of the child's home environment and maternal traits and behavior 9

\footnotetext{
${ }^{8}$ More specifically, this condition refers to women who smoked or drank alcohol around 12 months before giving birth. However, the share of women who report not having had consumed alcohol or cigarettes in the NLSY97 is similar to the share in the entire U.S. population of non-pregnant women (CDC 2004).

${ }^{9}$ Starting in survey year 2006, only children 4 years and older were given the interviewer-administered assessments. Therefore, interview observations for children under the age of 4 are not available for many of the youngest children in the CNLSY79 sample. This is the main reason for the decrease in our sample size in our regression analysis.
} 
We focus on the total HOME score as well as on the two sub-scores focusing on cognitive stimulation and emotional support. The HOME questionnaire for children aged 0 to 1 includes questions that ask about the number of books the child has at home, whether the mother reads to the child, availability of toys, interaction with parents, parental attentiveness, discipline patterns, and frequency of outings. These responses to these questions are either answered by the mother or recorded from observations of an official home visitor, and the HOME scores are reported as simple summations of the scores from individual items in the questionnaire, with higher scores signifying a better home environment. We choose to focus on HOME scores at ages 0 to $1^{10}$ to minimize the concern that parents may systematically adjust their interactions with and investments in the child based on their assessment of the child's abilities as revealed through test scores or personal interactions.

\subsection{Cognitive and Non-Cognitive Assessments}

\subsubsection{Cognitive Assessments}

In our aim to better understand the sources and the nature of birth order effects, we expand the set of outcome variables beyond adult education attainment and earnings that have typically been the focus of existing literature and examine a wide range of early cognitive and non-cognitive test scores. Specifically, children's cognitive outcomes are proxied by scores on the Peabody Individual Achievement Test - Mathematics (PIAT-M) and - Reading (PIAT-R) tests and the Peabody Picture Vocabulary Test (PPVT). All three assessments have been used extensively in a myriad of studies assessing the cognitive development of young children $[1]$

The PPVT is a vocabulary test administered to children between the ages of 3 through

\footnotetext{
${ }^{10}$ The CNLSY79 is administered every two years. Therefore, we calculate HOME scores as equal to the scores at age 0 . If scores are missing at age 0 , we use scores at age 1 . In our estimation sample, only 51 observations have scores from both ages 0 and 1 . Treating scores from age 1 as the primary measure does not alter our conclusions.

${ }^{11}$ Descriptions of the cognitive and non-cognitive assessments, prenatal and postnatal inputs, and early home environment are drawn from the NLSY79 online guides to Child and Young Adult Data available at: http://www.nlsinfo.org/childya/nlsdocs/guide/topicalTOC.html. Accessed on April 28, 2012.
} 
18 and is widely recognized to be a good measure of cognitive ability, especially of verbal intelligence. It has been found to be highly correlated with scores on other intelligence tests and is viewed to be an important indicator of early and middle school outcomes (Baker, Keck, Mott and Quinlan 1993). We focus on PPVT scores from ages 4 and 5 and from ages 10 and 11 in an effort to examine how the scores change from the earliest ages for which we have test score information to the beginning of adolescence.

The PIAT-R is a test designed to assess word recognition and pronunciation ability and is divided into two parts. The PIAT-R: Reading Recognition assesses skills such as matching letters, naming names, and reading single words aloud. The second part, PIAT-R: Reading Comprehension measures the child's ability to derive meaning from sentences that are read silently. PIAT-M assesses knowledge and application of mathematical concepts and facts. Both the PIAT-R and the PIAT-M tests are administered to children between 5 to 18 years old. In our analysis, we examine test scores at ages 5 and 6 and at ages 12 and 13, the earliest and the latest ages for which we have score information for the majority of our children in our sample.

The top panel of Table 2 presents the descriptive statistics for these cognitive tests, where we restrict the sample to those children for whom we have information about their prenatal investments and birth outcomes ${ }^{12}$ Since the test scores are age-standardized, differences in the means should not reflect the effect of age at test-taking. Nevertheless, except in the case of reading comprehension, children tend to perform slightly better in their second assessment.

\subsubsection{Non-Cognitive Assessments}

While cognitive assessments are important measures of children's early achievement, they, by themselves, may fail to capture critical differences in the children's mental and social

\footnotetext{
${ }^{12}$ Although this restriction does not ensure that the sample for which the means are reported is the same across PIAT and PPVT, our main empirical results hold when restricting the sample to those with both test scores.
} 
Table 2: Summary of Cognitive and Non-Cognitive Tests

\begin{tabular}{|c|c|c|c|}
\hline Variable & Mean & Std. Dev. & $\mathrm{N}$ \\
\hline \multicolumn{4}{|l|}{ Cognitive tests: } \\
\hline \multicolumn{4}{|l|}{ PPVT } \\
\hline 1st assessment (age 4 to 5 ) & 41.456 & 29.476 & 3232 \\
\hline 2nd assessment (age 10 to 11 ) & 49.144 & 29.637 & 4065 \\
\hline \multicolumn{4}{|l|}{ PIAT-M } \\
\hline 1st assessment (age 5 to 6 ) & 54.114 & 26.954 & 4776 \\
\hline 2nd assessment (age 12 to 13 ) & 57.138 & 26.643 & 3843 \\
\hline \multicolumn{4}{|l|}{ PIAT-R (Recognition) } \\
\hline 1st assessment (age 5 to 6 ) & 62.645 & 24.609 & 4687 \\
\hline 2nd assessment (age 12 to 13 ) & 61.360 & 28.256 & 3844 \\
\hline \multicolumn{4}{|l|}{ PIAT-R (Comprehension) } \\
\hline 1st assessment (age 5 to 6 ) & 72.518 & 18.471 & 1948 \\
\hline 2nd assessment (age 12 to 13 ) & 50.363 & 26.757 & 3813 \\
\hline \multicolumn{4}{|l|}{$\begin{array}{l}\text { Non-Cognitive tests: } \\
\text { BPI }\end{array}$} \\
\hline 1st assessment (age 4 to 5 ) & 56.024 & 27.427 & 4622 \\
\hline 2nd assessment (age 10 to 11 ) & 59.351 & 27.858 & 4188 \\
\hline \multicolumn{4}{|l|}{ MSD } \\
\hline 1st assessment (age 0 to 1 ) & 51.692 & 27.923 & 3087 \\
\hline 2nd assessment (age 2 to 3 ) & 53.033 & 28.091 & 3977 \\
\hline \multicolumn{4}{|l|}{ SPPC (Scholastic) } \\
\hline 1st assessment (age 8 to 9 ) & 171.167 & 41.457 & 2508 \\
\hline 2nd assessment (age 13 to 14 ) & 180.545 & 41.071 & 2943 \\
\hline \multicolumn{4}{|l|}{ SPPC (Global) } \\
\hline 1st assessment (age 8 to 9 ) & 204.041 & 33.354 & 2507 \\
\hline 2nd assessment (age 13 to 14 ) & 208.019 & 32.651 & 2943 \\
\hline
\end{tabular}

Notes: Weighted means. Standard deviations in parentheses and number of observations in brackets. Peabody Picture Vocabulary Test (PPVT), Peabody Individual Achievement Tests (PIAT), Behavioural Problem Index (BPI), and Motor and Social Development (MSD) are in age-standardized percentiles, while Self-Perception Profile for Children (SPPC) scores range from 0 to 250.

development (Heckman et al. 2006). To investigate whether birth order differences are found in non-cognitive outcomes, we focus on three assessments in the CNLSY79: the Behavior Problems Index (BPI), the Self-Perception Profile for Children (SPPC), and the Social Motor and Social Development Scale (MSD). Their descriptive statistics are presented in the bottom panel of Table 2 
The BPI measures the incidence and the severity of behavior problems for children of four years and older (Peterson and Zill 1986). The specific set of questions varies according to the age of the child. In our analysis, we examine the BPI Total Score which is based on responses from mothers to 28 questions regarding specific behaviors that her children may have exhibited in the previous three months. The higher the score, the greater the level of behavioral problems. We focus on BPI scores at ages 4 and 5 and at ages 10 and 11, the earliest ages for which we have scores to the beginning of adolescence.

The SPPC is a measure of a child's sense of general self-worth and self-competence in their academic skills based on the child's self-reported answers to the interviewer's verbal questions. The score is divided into two sub-scores: a scholastic competence score and a global self-worth score. In the SPPC survey, each child is given a choice to select the the former or the latter part of a two-part statement that describes him or her the best and indicate the extent to which the description is true for them ${ }^{13}$ The SPPC is completed by children eight years and older in the survey years 1986 to 1994, and beginning in 1996, the assessment was limited to children who were 12 years and older. We examine the SPPC scores at ages 8 and 9 and at ages 13 and 14 .

Finally, developed by the National Center for Health Statistics to measure motor, social, and cognitive development of young children from birth to three years, the MSD is based on the mother's answer to fifteen or sixteen age-appropriate questions about their child's development. We examine the MSD scores at ages 0 and 1 and at ages 2 and 3 .

\subsection{Birth Order and Additional Controls}

In our analysis of whether there exists significant differences in early cognitive and noncognitive outcomes across siblings of different birth order, our empirical specifications also control for other child characteristics that can potentially affect the mother's prenatal and postnatal investment choices. More specifically, in addition to birth order, we control for

\footnotetext{
${ }^{13}$ For example, a statement on the SPPC part of the survey declares, "Some kids feel like they are just as smart as other kids their ages, but other kids aren't so sure and wonder if they are as smart."
} 
Table 3: Summary of Child's and Family Characteristics at Birth

\begin{tabular}{lcclcc}
\hline \hline Child's characteristics & Mean & Std. Dev. & Family characteristics at birth & Mean & Std. Dev. \\
\hline Birth order & & & & & \\
$\quad$ first & 0.437 & 0.496 & Income at birth & 45,647 & 11,705 \\
second & 0.366 & 0.482 & Welfare recipient & 0.193 & 0.395 \\
third & 0.144 & 0.351 & Amount in welfare & 862.58 & 3224 \\
$\quad$ fourth or higher & 0.054 & 0.225 & LF: employed & 0.630 & 0.483 \\
Boy & 0.523 & 0.500 & LF: unemployed & 0.086 & 0.280 \\
Twins & 0.019 & 0.137 & LF: out of LF & 0.279 & 0.448 \\
Mother's age at birth & 24.988 & 4.069 & LF: military & 0.005 & 0.072 \\
\hline $\mathrm{N}$ & 5254 & & & 5254 & \\
\hline \hline
\end{tabular}

Notes: Weighted means. LF stands for Labor Force. Sample limited to children with complete information on prenatal investments and birth outcomes. Income and welfare payments in 1983 dollars.

the sex of the child, the age of the mother at child's birth, and whether it was a twin birth. Table 3 shows the descriptive statistics of mothers who consistently reported all the outcome variables considered in our analysis. Most children in our sample are first-borns, $43.7 \%$, while $36.6 \%$ are second children. Less than $20 \%$ of the children are born to mothers who already have two kids, and only $2 \%$ of the children in our sample were a part of a multiple birth. Because our sample is comprised of births that occurred from 1979 to 1998, mothers were on average 25 years old when they gave birth. In our regressions, we include year of birth dummies to account for any cohort effects and any policy changes or new medical recommendations that could confound our estimates.

Although we rely on the family fixed effects model in all of our empirical specifications, there may be other time-varying family characteristics around the time of the child's birth that may impact our outcomes of interest, such as income or welfare eligibility. These variables are likely to be correlated, directly or indirectly through the mother's age at pregnancy, with birth order. Therefore, in our regression specifications, we also control for several key family characteristics at birth, including family income, welfare payments, and the mother's labor force attachment. The average total family income at the child's birth is $\$ 45,647$ in 
1983 dollars, and around $20 \%$ of the children in our sample were born to mothers who were welfare recipients at the child's birth. We also control for the mother's labor force status during the year prior to the birth ${ }^{14}$ Regrettably, the NLSY79 does not include consistent information on Medicaid eligibility and coverage, which may account for some of the differences on prenatal care utilization and birth outcomes.

\section{Results}

To measure the effect of birth order on a range of outcomes, we estimate the following equation:

$$
Y_{i f t}=\alpha+\beta \mathrm{D}(\text { birth order })_{i f}+\gamma X_{i}+\delta X_{f t}+v_{f}+\varepsilon_{i f t}
$$

where $i$ denotes child, $f$ family, and $Y_{i f t}$ the outcome of interest at age $t$. D(birth order $)_{i f}$ are four dummies for the second, third, and higher order of birth, leaving the first borns as the omitted category. $X_{i}$ are child-specific characteristics (gender, twin, age of the mother at birth, and cohort and region indicators), and $X_{f t}$ are time-varying family characteristics (income, welfare recipient, labor force participation).15 $v_{f}$ are family-fixed effects. Models with cognitive and non-cognitive tests as the outcome of interest also control for age in months at the time of the assessment, because the CNLSY79 is administered every two years and can introduces a significant age variation at the time of testing of up to 24 months. For the sake of simplicity, we assume linearity and continuity for all models with dummy or count variables as the dependent variable. All models are weighted and standard errors are corrected for heteroskedasticity.

\footnotetext{
${ }^{14}$ We choose to control for the mother's employment status a year before birth rather than at birth to minimize the possibility that the mother's labor force decisions are correlated with the status of her pregnancy and child's birth outcomes. However, using the mother's labor force status at birth does not change our main results.

${ }^{15}$ Family characteristics at the time of outcome are only included for prenatal and early postnatal investments. Including contemporaneous controls at the family level for later outcomes does not affect the results.
} 
Table 4: Prenatal Investments and Birth Outcomes

\begin{tabular}{|c|c|c|c|c|c|c|}
\hline Prenatal Investments: & $\begin{array}{c}\text { \# of drinks } \\
\text { per week }\end{array}$ & $\begin{array}{c}\text { Reduced } \\
\text { alcohol }\end{array}$ & $\begin{array}{c}\text { \# cigarettes } \\
\text { per day }\end{array}$ & $\begin{array}{l}\text { Reduced } \\
\text { smoking }\end{array}$ & $\begin{array}{c}\text { Delayed } \\
\text { prenatal care }\end{array}$ & $\begin{array}{l}\text { Month of 1st } \\
\text { prenatal visit }\end{array}$ \\
\hline & $(1)$ & $(2)$ & $(3)$ & $(4)$ & $(5)$ & $(6)$ \\
\hline 2nd born & $\begin{array}{l}-0.772 \\
(0.588)\end{array}$ & $\begin{array}{l}-0.037 \\
(0.044)\end{array}$ & $\begin{array}{c}0.536 \\
(0.538)\end{array}$ & $\begin{array}{c}-0.090^{*} \\
(0.048)\end{array}$ & $\begin{array}{l}-0.038 \\
(0.027)\end{array}$ & $\begin{array}{l}0.098^{*} \\
(0.057)\end{array}$ \\
\hline 3rd born & $\begin{array}{l}-1.384 \\
(0.988)\end{array}$ & $\begin{array}{l}-0.035 \\
(0.076)\end{array}$ & $\begin{array}{l}-0.599 \\
(0.771)\end{array}$ & $\begin{array}{c}-0.175^{* *} \\
(0.078)\end{array}$ & $\begin{array}{l}-0.036 \\
(0.049)\end{array}$ & $\begin{array}{c}0.221^{* *} \\
(0.093)\end{array}$ \\
\hline 4th or higher born & $\begin{array}{l}-2.752 \\
(1.783)\end{array}$ & $\begin{array}{l}-0.114 \\
(0.113)\end{array}$ & $\begin{array}{l}-1.164 \\
(1.081)\end{array}$ & $\begin{array}{c}-0.301^{* *} \\
(0.125)\end{array}$ & $\begin{array}{l}-0.018 \\
(0.071)\end{array}$ & $\begin{array}{c}0.357^{* *} \\
(0.144)\end{array}$ \\
\hline F-stat & 1.550 & 1.251 & 1.243 & 2.706 & 1.043 & 2.974 \\
\hline $\mathrm{R}^{2}$ & 0.086 & 0.075 & 0.070 & 0.162 & 0.019 & 0.055 \\
\hline $\mathrm{N}$ & 2468 & 2468 & 1790 & 1790 & 5254 & 4298 \\
\hline Birth Outcomes: & $\begin{array}{c}\text { Gestational } \\
\text { length }\end{array}$ & $\begin{array}{l}\text { Premature } \\
\text { (weeks }<37 \text { ) }\end{array}$ & Birth weight & $\begin{array}{c}\text { Low birth } \\
\text { weight }\end{array}$ & $\begin{array}{l}\text { Overweight } \\
\text { at birth }\end{array}$ & $\begin{array}{l}\text { Baby } \\
\text { length }\end{array}$ \\
\hline 2nd born & $\begin{array}{l}-0.221 \\
(0.151)\end{array}$ & $\begin{array}{c}-0.074^{*} \\
(0.038)\end{array}$ & $\begin{array}{c}2.965^{* * *} \\
(1.126)\end{array}$ & $\begin{array}{l}-0.020 \\
(0.015)\end{array}$ & $\begin{array}{c}0.027 \\
(0.023)\end{array}$ & $\begin{array}{c}0.027 \\
(0.098)\end{array}$ \\
\hline 3rd born & $\begin{array}{l}-0.321 \\
(0.281)\end{array}$ & $\begin{array}{l}-0.095 \\
(0.066)\end{array}$ & $\begin{array}{l}4.227^{*} \\
(2.206)\end{array}$ & $\begin{array}{l}-0.034 \\
(0.028)\end{array}$ & $\begin{array}{l}0.076^{*} \\
(0.040)\end{array}$ & $\begin{array}{l}-0.045 \\
(0.196)\end{array}$ \\
\hline 4th or higher born & $\begin{array}{c}-0.352 \\
(0.493)\end{array}$ & $\begin{array}{l}-0.049 \\
(0.102)\end{array}$ & $\begin{array}{c}2.167 \\
(3.609)\end{array}$ & $\begin{array}{l}-0.038 \\
(0.042)\end{array}$ & $\begin{array}{l}0.110^{*} \\
(0.061)\end{array}$ & $\begin{array}{l}-0.290 \\
(0.328)\end{array}$ \\
\hline F-stat & 1.379 & 2.189 & 4.992 & 1.800 & 1.921 & 2.511 \\
\hline $\mathrm{R}^{2}$ & 0.063 & 0.038 & 0.111 & 0.080 & 0.043 & 0.057 \\
\hline $\mathrm{N}$ & 5254 & 5254 & 5254 & 5254 & 5254 & 5254 \\
\hline
\end{tabular}

Notes: All regressions are weighted and include family fixed effects. Robust standard errors in parentheses. $*=$ different from zero at the $10 \%$ level. ${ }^{* *}=$ different from zero at the $5 \%$ level. ${ }^{* * *}=$ different from zero at the $1 \%$ level. All specifications control for regional dummies, maternal age, gender of the child, income of the family, lagged labor force status of the mother and welfare status and amount received in welfare, if any. A series of dummies on year of birth are also included. Alcohol consumption and smoking are defined for woman who reported drinking or smoking prior to the pregnancy. Prenatal care is classified as delayed if the first visit occurred at the 4th gestational month of pregnancy or later. Month of 1st prenatal visit is defined only for women who seek prenatal care early in their pregnancies (up to the 3rd gestational month) 


\subsection{Differences in Early Investments and Birth Outcomes by Birth Order}

In this section, we examine whether there exist significant variations in pre- and postnatal investments, key birth outcomes, and child's early home environment across children of different birth order. Table 4 presents the results for prenatal and birth outcomes, and Table 5 presents the results for postnatal investments.

The top panel of Table 4 shows that, within the same family, there are significant differences in some measures of prenatal investments across siblings of different birth order. However, these patterns are not robust across all investment measures. First, we fail to find statistically significant differences in the probability of alcohol reduction during pregnancy across birth order, although the point estimates are sizable. However, while still not statistically significant, the average number of drinks per week tend to decrease with birth order as well. This pattern may be driven by women reducing their overall alcohol consumption as they age and family size increases ${ }^{16}$

In contrast to alcohol consumption patterns, we find that the probability of reducing cigarette smoking is significantly lower for higher order children. Compared to her first child, a woman who was a prior smoker is 9 percentage points less likely to reduce cigarette consumption during the pregnancy of her second child, 17.5 percentage points less likely while carrying her third child, and 30 percentage points less likely for her 4th or higher

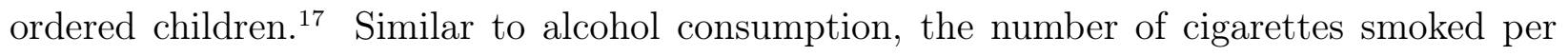
day also tend to decrease, although still not significantly 18

Finally, while we find no evidence that women are more likely to delay their first prenatal care visit for her latter children, column 6 of Table 4 shows that among those women who

\footnotetext{
${ }^{16}$ Note that births occurred between 1980 and 1994, when the negative effects of smoking or drinking during pregnancy were already well established.

${ }^{17}$ Unfortunately, we do not have information on the timing of the reduction in smoking. Stopping tobacco consumption early in the pregnancy has been reported to be correlated with better birth outcomes than stopping at a later point (MacArthur and Knox 1988).

${ }^{18}$ Fingerhut, Kleinman and Kendrick (1990) report a relapse ratio of 70 percent within a year of birth in the mid 1980s.
} 
sought timely prenatal care, mothers are significantly more likely to postpone their first visit for higher order children 19 The effect of early prenatal care on children in literature is still not well established. While some studies only find a weak impact of prenatal care on birth outcomes (Currie and Grogger 2002), others, such as Smith-Conway and Deb (2005), report that for normal pregnancies, a delay of one week in first prenatal visit is associated with a decrease of 1 to 1.2 ounces in birth weight ${ }^{20}$

Despite our finding that mothers are less likely to reduce cigarette consumption and to seek timely prenatal care with her latter pregnancies, the birth outcomes of higher-order children do not seem to be adversely affected. The bottom panel of Table 4 presents the regression results for birth outcomes. Siblings born later are slightly less likely to be premature, and consequently, are more likely to be heavier (but not taller) than their older siblings. The effect of birth order on weight is ambiguous. Columns 3 and 4 show that while higher order children are less likely to suffer from low birth weight, they are also significantly more likely to be born overweight. Being overweight at birth has been shown to be associated with higher BMI later in life $\AA^{21}$ and increased risk for obesity and diseases such as cancer, asthma, and atopy in adults. ${ }^{22}$ Therefore, this positive relationship between birth order and increased probability of being overweight at birth may serve as a potential explanation for

\footnotetext{
${ }^{19}$ The absence of statistically significant differences in our dataset may be due to the relatively small size of our sample. Using a larger sample of birth certificates, Lewis, Mathews and Heuser (1996) report a positive correlation between delayed prenatal care and pregnancies after the second live birth.

${ }^{20}$ Drinking alcohol, smoking, delayed access to prenatal care are also associated with a higher incidence of miscarriage and activities such as drug consumption that can cause fetal losses (e.g. Dominguez-Rojas, de Juanes-Pardo, Astasio-Arbiza, Ortega-Molina and Gordillo-Florencio 1994). Unfortunately, the CNLSY79 does not include information on pregnancies that ended in spontaneous or induced abortion. Risky activities would be higher for pregnancies that end in fetal loss and the children would have performed significantly worse, would they not have miscarried. If the incidence of these "non-random" fetal losses varies by previous birth histories of the women, its omission from the sample might affect our estimation. However, the proportion of heavy drinkers or heavy smoker in our sample is limited and does not appear to vary by birth order.

${ }^{21}$ For example, see Gillman, Rifas-Shiman, Berkey, Field and Colditz (2003), Leong, Mignone, Newcomb, Titus-Ernstoff, Baron, Trentham-Dietz, Stampfer, Willett and Egan (2003), Parsons, Power, Logan, Summerbell et al. (1999), Pietiläinen, Kaprio, Räsänen, Winter, Rissanen and Rose (2001), and Wei, Li, Sung, Lin, Chiang, Li and Chuang (2007).

${ }^{22}$ See Eriksson, Wedel, Wallander, Krakau, Hugosson, Carlsson and Svärdsudd (2007), Harder, Plagemann and Harder (2008), Hjalgrim, Westergaard, Rostgaard, Schmiegelow, Melbye, Hjalgrim and Engels (2003), and Remes, Patel, Hartikainen, Jarvelin and Pekkanen (2008).
} 
Table 5: Postnatal Investment

\begin{tabular}{lccccc}
\hline \hline & Breastfeed & $\begin{array}{c}\text { Weeks } \\
\text { Breastfed }\end{array}$ & $\begin{array}{c}\text { HOME } \\
\text { (Total) }\end{array}$ & $\begin{array}{c}\text { HOME } \\
\text { (Cognitive) }\end{array}$ & $\begin{array}{c}\text { HOME } \\
\text { (Emotion) }\end{array}$ \\
\hline \multirow{4}{*}{ 2nd born } & $(1)$ & $(2)$ & $(3)$ & $(4)$ & $(5)$ \\
& $-0.098^{* * *}$ & 1.217 & $-5.591^{* * *}$ & $-2.734^{* *}$ & $-2.354^{* *}$ \\
3rd born & $(0.021)$ & $(1.631)$ & $(1.788)$ & $(1.069)$ & $(1.075)$ \\
& $-0.122^{* * *}$ & 4.333 & $-7.564^{* *}$ & $-5.184^{* * *}$ & -1.933 \\
4th or higher born & $(0.038)$ & $(2.987)$ & $(3.365)$ & $(1.992)$ & $(2.018)$ \\
& $-0.136^{* *}$ & 7.679 & -8.111 & $-5.486^{*}$ & -1.895 \\
F-stat & $(0.058)$ & $(5.395)$ & $(5.396)$ & $(3.209)$ & $(3.142)$ \\
$\mathrm{R}^{2}$ & & & & & \\
$\mathrm{~N}$ & 2.395 & 1.591 & 6.679 & 12.394 & 2.301 \\
\hline \hline
\end{tabular}

Notes: All regressions are weighted and include family fixed effects. Robust standard errors in parentheses. ${ }^{*}=$ different from zero at the $10 \%$ level. ${ }^{* *}=$ different from zero at the $5 \%$ level. $* * *=$ different from zero at the $1 \%$ level. All specifications control for regional dummies, maternal age, gender of the child, income of the family, lagged labor force status of the mother and welfare status and amount received in welfare, if any. A series of dummies on year of birth are also included.

worse adult outcomes through its impact on health.

Although we do not find much evidence of subtantially adverse birth outcomes for children of higher birth order, Table 5 reveals a clear pattern of maternal underinvestment after birth in later-born children. Compared to firstborns, mothers are 10 to 14 percentage points less likely to breastfeed their younger children. However, conditional on being breastfed, there are no clear patterns in the relationship between the duration of breastfeeding and birth order. While the signs and magnitudes of the length of breastfeeding indicate a positive relationship between breastfeeding duration and birth order, the standard errors are too large to establish statistical significance. In light of the growing evidence that breastfeeding at birth, when compared with formula-feeding, is associated with better early health and cognitive outcomes ${ }^{23}$ the significant negative relationship between the probability of

\footnotetext{
${ }^{23}$ For example, see Belfield and Kelly (2010), Oddy, Kendall, Blair, De Klerk, Stanley, Landau, Silburn and Zubrick (2003), Chung, Raman, Chew, Magula, Trikalinos and Lau (2007), Horwood and Fergusson (1998). Note, however, that none of these studies assess results from a randomized controlled study or utilize a natural experiment in the choice to breastfeed or not. All of the studies attempt to mitigate the problem of endogeneity in the choice to breastfeed by simply including a large set of controls on family or
} 
breastfeeding and birth order may potentially be a part of the explanation for worse adult outcomes in latter-born children.

Finally, the level of home investment as proxied by the HOME scores has been shown to be significant correlates of later cognitive achievement and health (Todd and Wolpin 2007, Strauss and Knight 1999, Carlson and Corcoran 200124, and we find large and significant birth order differences in the HOME scores across all dimensions as reported in the last three columns of Table 5. Compared to the first child, latter-born children are associated with worse home environments - both in cognitive stimulation and emotional support - by nearly 3 to 9 points or approximately 0.2 to 0.35 standard deviations on the HOME score scale. This negative relationship is especially pronounced for the cognitive home environment score, where there exists a monotonically decreasing relationship between the quality of the home environment and birth order.

\subsection{Birth Order and Test Scores}

Having established that there are significant differences in cigarette usage, prenatal care, breastfeeding, and early home environment across siblings of different birth order, we now turn to the main research questions that we seek to address in this paper. First, are there birth order effects in early cognitive and non-cognitive outcomes that mirror the patterns found in adult outcomes? Second, if yes, can variations in pre and postnatal investments, birth outcomes, and early home environments within a family explain these birth order effects in cognitive and non-cognitive assessments?

Tables 6 and 7 and Tables 8 and 9 present our results for a wide range of cognitive and non-cognitive test scores, respectively. For both types of assessments, all of the analyses below use age-standardized percentile scores that are transformations of the raw scores that were originally designed to have a normal distribution with a mean of 100 and a standard child characteristics or performing propensity score matching using these sets of controls.

${ }^{24}$ Todd and Wolpin (2007) find that equalizing home inputs at the average levels of white children would close the black-white and the Hispanic-white test score gaps in math and reading about 10 to $20 \%$. 
deviation of 15. For ease of interpretation, all scores have been normalized to have a standard deviation of 1 throughout the paper. Therefore, the regression coefficients show the change in standard deviations of the test score by a one unit increase in the explanatory variable.

\subsubsection{Cognitive Test Scores}

Tables 6 and 7 examine birth order effects for early and later cognitive assessments for PPVT, PIAT-M, and PIAT-R tests. The odd columns of Tables 6 and 7 report regression results without early childhood controls while the even columns report results controlling for prenatal investment, birth outcomes, and postnatal investments, including HOME scores ${ }^{25}$

We first focus on discussing the results in odd columns of Tables 6 and 7 without early childhood controls. Consistent with the existing literature on adult education and earnings, children of higher birth order tend to score significantly lower across several cognitive assessments. However, this negative relationship between test scores and birth order is not statistically robust across all assessments. For the PPVT, the birth order effect is only evident and significant in the second assessment (column 3). Compared to first-borns, second-born children score about 0.2 standard deviations lower at age 10 to 11 while the third and the higher ordered children score about 0.3 standard deviations lower. This increase in magnitude and significance of the birth order effect by time of second assessment may be due to differences in unobserved parental investments between the ages of 4-5 and 10-11 by birth order or the effect being latent until age 10-11. To place the magnitudes of these birth order effects in perspective, note that Lang and Sepulveda (2007) find a black-white gap in the PPVT at ages 3 to 4 of about 0.5 standard deviations after controlling for a myriad of mother and family controls, including mother's AFQT, parental interactions and the HOME score, pregnancy and early life history, and family structure. Thus, a gap of 0.2 to 0.3 standard deviations among siblings in the same family is quite substantial. While the coefficients on higher birth order dummies are remain predominantly negative for the mathematics portion

\footnotetext{
${ }^{25}$ To minimize the dramatic sample reduction due to missing HOME scores, we replace missing HOME scores with zero and include an indicator for missing.
} 
Table 6: Cognitive Test Scores: PPVT and PIAT-M

\begin{tabular}{|c|c|c|c|c|c|c|c|c|}
\hline & \multicolumn{4}{|c|}{$P P V T$} & \multicolumn{4}{|c|}{ PIAT-M } \\
\hline & \multicolumn{2}{|c|}{$\begin{array}{l}\text { 1st assessment } \\
\text { (Ages } 4 \text { to } 5 \text { ) }\end{array}$} & \multicolumn{2}{|c|}{$\begin{array}{l}\text { 2nd assessment } \\
\text { (Ages } 10 \text { to 11) }\end{array}$} & \multicolumn{2}{|c|}{$\begin{array}{l}\text { 1st assessment } \\
\text { (Ages } 5 \text { to } 6)\end{array}$} & \multicolumn{2}{|c|}{$\begin{array}{l}\text { 2nd assessment } \\
\text { (Ages } 12 \text { to } 13 \text { ) }\end{array}$} \\
\hline & $(1)$ & $(2)$ & $(3)$ & $(4)$ & $(5)$ & $(6)$ & $(7)$ & $(8)$ \\
\hline 2nd born & $\begin{array}{l}-0.001 \\
(0.081)\end{array}$ & $\begin{array}{c}0.012 \\
(0.080)\end{array}$ & $\begin{array}{c}-0.215^{* * *} \\
(0.055)\end{array}$ & $\begin{array}{c}-0.219^{* * *} \\
(0.057)\end{array}$ & $\begin{array}{l}-0.073 \\
(0.062)\end{array}$ & $\begin{array}{l}-0.058 \\
(0.064)\end{array}$ & $\begin{array}{l}-0.078 \\
(0.055)\end{array}$ & $\begin{array}{l}-0.082 \\
(0.054)\end{array}$ \\
\hline 3rd born & $\begin{array}{l}-0.141 \\
(0.135)\end{array}$ & $\begin{array}{l}-0.120 \\
(0.131)\end{array}$ & $\begin{array}{c}-0.289^{* * *} \\
(0.094)\end{array}$ & $\begin{array}{c}-0.291^{* * *} \\
(0.096)\end{array}$ & $\begin{array}{l}-0.041 \\
(0.101)\end{array}$ & $\begin{array}{l}-0.021 \\
(0.102)\end{array}$ & $\begin{array}{l}-0.067 \\
(0.099)\end{array}$ & $\begin{array}{l}-0.074 \\
(0.101)\end{array}$ \\
\hline 4th or higher born & $\begin{array}{l}-0.047 \\
(0.237)\end{array}$ & $\begin{array}{l}-0.038 \\
(0.229)\end{array}$ & $\begin{array}{c}-0.346^{* *} \\
(0.143)\end{array}$ & $\begin{array}{c}-0.344^{* *} \\
(0.144)\end{array}$ & $\begin{array}{l}-0.034 \\
(0.150)\end{array}$ & $\begin{array}{l}-0.016 \\
(0.152)\end{array}$ & $\begin{array}{c}0.007 \\
(0.147)\end{array}$ & $\begin{array}{l}-0.024 \\
(0.149)\end{array}$ \\
\hline F-stat & 1.205 & 0.885 & 1.299 & 1.460 & 1.745 & 1.539 & 2.177 & 1.536 \\
\hline $\mathrm{R}^{2}$ & 0.048 & 0.056 & 0.019 & 0.040 & 0.031 & 0.041 & 0.044 & 0.053 \\
\hline $\mathrm{N}$ & 3232 & 3232 & 4065 & 4065 & 4776 & 4776 & 3843 & 3843 \\
\hline \multicolumn{9}{|c|}{ Controls (F-stat test of joint significance) } \\
\hline prenatal investments & $\mathrm{n} / \mathrm{a}$ & 0.10 & $\mathrm{n} / \mathrm{a}$ & 1.32 & $\mathrm{n} / \mathrm{a}$ & 0.76 & $\mathrm{n} / \mathrm{a}$ & 0.21 \\
\hline birth outcomes & $\mathrm{n} / \mathrm{a}$ & 0.67 & $\mathrm{n} / \mathrm{a}$ & $2.31^{* *}$ & $\mathrm{n} / \mathrm{a}$ & 0.89 & $\mathrm{n} / \mathrm{a}$ & 1.26 \\
\hline postnatal investments & $\mathrm{n} / \mathrm{a}$ & 0.97 & $\mathrm{n} / \mathrm{a}$ & 0.69 & $\mathrm{n} / \mathrm{a}$ & 1.02 & $\mathrm{n} / \mathrm{a}$ & 0.57 \\
\hline All controls & $\mathrm{n} / \mathrm{a}$ & 0.59 & $\mathrm{n} / \mathrm{a}$ & $1.54^{*}$ & $\mathrm{n} / \mathrm{a}$ & 0.76 & $\mathrm{n} / \mathrm{a}$ & 0.74 \\
\hline
\end{tabular}

Notes: All regressions are weighted and include family fixed effects. Robust standard errors in parentheses. $*=$ different from zero at the $10 \%$ level. ${ }^{* *}=$ different from zero at the $5 \%$ level. ${ }^{* *}=$ different from zero at the $1 \%$ level. All assessments are standardized to have a mean of 0 and a standard deviation of 1 . All specifications control for regional dummies, maternal age and weight at birth and before pregnancy, gender of the child, twining, age of the child in months at the time of the test and a series of dummies for year of birth. 
Table 7: Cognitive Test Scores: PIAT-R (Recognition) and PIAT-R (Comprehension)

\begin{tabular}{|c|c|c|c|c|c|c|c|c|}
\hline & \multicolumn{4}{|c|}{ PIAT-R (Recognition) } & \multicolumn{4}{|c|}{ PIAT-R (Comprehension) } \\
\hline & \multicolumn{2}{|c|}{$\begin{array}{l}\text { 1st assessment } \\
\text { (Ages } 5 \text { to } 6)\end{array}$} & \multicolumn{2}{|c|}{$\begin{array}{l}\text { 2nd assessment } \\
\text { (Ages } 12 \text { to } 13 \text { ) }\end{array}$} & \multicolumn{2}{|c|}{$\begin{array}{l}\text { 1st assessment } \\
\text { (Ages } 5 \text { to } 6)\end{array}$} & \multicolumn{2}{|c|}{$\begin{array}{l}\text { 2nd assessment } \\
\text { (Ages } 12 \text { to 13) }\end{array}$} \\
\hline & (1) & $(2)$ & $(3)$ & $(4)$ & $(5)$ & (6) & $(7)$ & (8) \\
\hline 2nd born & $\begin{array}{c}-0.217^{* * *} \\
(0.057)\end{array}$ & $\begin{array}{c}-0.245^{* * *} \\
(0.058)\end{array}$ & $\begin{array}{c}-0.163^{* * *} \\
(0.057)\end{array}$ & $\begin{array}{c}-0.170^{* * *} \\
(0.058)\end{array}$ & $\begin{array}{l}-0.035 \\
(0.110)\end{array}$ & $\begin{array}{l}-0.059 \\
(0.111)\end{array}$ & $\begin{array}{c}-0.244^{* * *} \\
(0.067)\end{array}$ & $\begin{array}{c}-0.246^{* * *} \\
(0.067)\end{array}$ \\
\hline 3rd born & $\begin{array}{c}-0.199 * * \\
(0.096)\end{array}$ & $\begin{array}{c}-0.236^{* *} \\
(0.098)\end{array}$ & $\begin{array}{l}-0.204^{*} \\
(0.109)\end{array}$ & $\begin{array}{l}-0.210^{*} \\
(0.109)\end{array}$ & $\begin{array}{l}-0.084 \\
(0.202)\end{array}$ & $\begin{array}{l}-0.185 \\
(0.206)\end{array}$ & $\begin{array}{c}-0.291^{* *} \\
(0.117)\end{array}$ & $\begin{array}{c}-0.298^{* *} \\
(0.117)\end{array}$ \\
\hline 4th or higher born & $\begin{array}{c}-0.371^{* *} \\
(0.145)\end{array}$ & $\begin{array}{c}-0.422^{* * *} \\
(0.147)\end{array}$ & $\begin{array}{c}-0.267^{*} \\
(0.155)\end{array}$ & $\begin{array}{l}-0.283^{*} \\
(0.153)\end{array}$ & $\begin{array}{c}0.145 \\
(0.282)\end{array}$ & $\begin{array}{c}0.109 \\
(0.282)\end{array}$ & $\begin{array}{c}-0.386^{* *} \\
(0.172)\end{array}$ & $\begin{array}{c}-0.390^{* *} \\
(0.172)\end{array}$ \\
\hline $\begin{array}{l}\text { F-stat } \\
\mathrm{R}^{2} \\
\mathrm{~N}\end{array}$ & $\begin{array}{c}4.789 \\
0.084 \\
4687\end{array}$ & $\begin{array}{c}3.624 \\
0.099 \\
4687\end{array}$ & $\begin{array}{l}1.142 \\
0.016 \\
3844\end{array}$ & $\begin{array}{l}1.146 \\
0.029 \\
3844\end{array}$ & $\begin{array}{c}12.215 \\
0.368 \\
1948\end{array}$ & $\begin{array}{c}9.535 \\
0.422 \\
1948\end{array}$ & $\begin{array}{l}2.812 \\
0.052 \\
3813\end{array}$ & $\begin{array}{l}2.313 \\
0.068 \\
3813\end{array}$ \\
\hline $\begin{array}{l}\text { Controls (F-stat test of } \\
\text { prenatal investments } \\
\text { birth outcomes } \\
\text { postnatal investments } \\
\text { All controls }\end{array}$ & $\begin{array}{l}\mathrm{n} / \mathrm{a} \\
\mathrm{n} / \mathrm{a} \\
\mathrm{n} / \mathrm{a} \\
\mathrm{n} / \mathrm{a}\end{array}$ & $\begin{array}{l}\text { ance) } \\
\qquad .48 \\
2.66^{* *} \\
1.09 \\
1.45^{*}\end{array}$ & $\begin{array}{l}\mathrm{n} / \mathrm{a} \\
\mathrm{n} / \mathrm{a} \\
\mathrm{n} / \mathrm{a} \\
\mathrm{n} / \mathrm{a}\end{array}$ & $\begin{array}{c}0.59 \\
1.87^{*} \\
0.65 \\
1.07\end{array}$ & $\begin{array}{l}\mathrm{n} / \mathrm{a} \\
\mathrm{n} / \mathrm{a} \\
\mathrm{n} / \mathrm{a} \\
\mathrm{n} / \mathrm{a}\end{array}$ & $\begin{array}{c}1.92^{*} \\
2.19^{* *} \\
1.23 \\
2.47^{* * *}\end{array}$ & $\begin{array}{l}\mathrm{n} / \mathrm{a} \\
\mathrm{n} / \mathrm{a} \\
\mathrm{n} / \mathrm{a} \\
\mathrm{n} / \mathrm{a}\end{array}$ & $\begin{array}{l}0.56 \\
1.38 \\
1.06 \\
1.20\end{array}$ \\
\hline
\end{tabular}

Notes: All regressions are weighted and include family fixed effects. Robust standard errors in parentheses. $*=$ different from zero at the $10 \%$ level. ${ }^{* *}=$ different from zero at the $5 \%$ level. ${ }^{* * *}=$ different from zero at the $1 \%$ level. All assessments are standardized to have a mean of 0 and a standard deviation of 1 . All specifications control for regional dummies, maternal age and weight at birth and before pregnancy, gender of the child, twining, age of the child in months at the time of the test and a series of dummies for year of birth. 
of the PIAT, we do not find statistically significant differences across siblings of different birth order.

Turning to the PIAT-Reading tests in Table 7, we find evidence that children of higher birth order perform significantly worse on the PIAT-R Recognition test at both early and later assessments. At ages 5 to 6 , a second-born and a third-born will score 0.2 standard deviations lower on the PIAT-R Recognition test, while fourth and higher birth order children will score 0.37 standard deviations lower (column 1). These negative birth order effects are sustained in both their magnitude and statistical significance at the beginning of their adolescence (column 3). While there is no evidence of birth order effects in the comprehension portion of PIAT-R at ages 5 to 6 , we find large and statistically significant differences in the second assessment, with younger children scoring 0.25 to 0.4 standard deviations lower compared to the first-born in the same family. These results are robust to changing the age of 2 nd assessment, and to restricting the sample to children who took both tests. The sizes of these birth order effects are notable considering that they are similar to the black-white gap in the PIAT-R scores of 0.3 to 0.4 standard deviations found in Fryer and Levitt (2004) at grade 5 and significantly larger than the black-white gap of 0.17 standard deviations reported in Lang and Sepulveda (2007) for the same age group after controlling for the mother's AFQT.

In summary, with the exception of PIAT-Mathematics for which we do not find evidence of birth order effects at either the first or the second assessment, we find strong evidence of a large negative relationship between birth order and test scores, especially at ages 10 to 13 . The magnitudes of these birth effects are fairly consistent across all tests, with the secondborn scoring about 0.2 standard deviations lower than the first-born and the higher-order children scoring lower by 0.3 to 0.4 standard deviations.

To investigate whether these birth order effects found in PPVT and PIAT-R Recognition tests are robust to accounting for differences in pre/postnatal investments, birth outcomes, and home environments, we add these controls in the even columns. Despite our finding that 
there some significant differences in early childhood conditions across children of different birth order, the observed differences in cognitive scores by birth order are robust to controlling for these factors. Neither the magnitude nor the statistical significance of the birth order effects is changed by the addition of these controls. Nonetheless, as we can see at the bottom of table 7 , birth outcomes are jointly significantly correlated with test scores ${ }^{26}$

\subsubsection{Non-Cognitive Tests}

We now test for the presence of birth order effects in non-cognitive assessments and investigate whether early childhood conditions can explain any differences in these alternative measures of children's mental and social development across children of different birth order in the same family. Tables 8 and 9 report these results.

Examining the Behavioral Problem Index (BPI) in columns (1) and (3) in Table 8, we find that younger siblings are reported to have less behavior problems than older children. At ages 10 to 11 , a child with two older siblings scores about 0.25 standard deviations lower than a first- or a second-born child. While not statistically significant in the first assessment, the point estimates are of still substantial magnitude. Although these results may be surprising given the strongly negative birth order effects in cognitive outcomes, we note that there exists some ambiguity in whether a lower BPI score truly captures what is a "better" behavior. For example, the BPI section of the CNLSY79 questionnaire includes subsections on measures of headstrongness and hyperactivity. While exhibiting greater stubbornness or hyperactivity may lead to higher BPI scores, one may be able to argue that these characteristics can be reflective of qualities that may have a positive influence on learning, risk-taking, and persistence.

Despite having lower BPI scores than their older siblings, younger children perform worse on the rest of non-cognitive assessments. We observe strong negative birth order effects in

\footnotetext{
${ }^{26}$ The significant effect of birth outcomes on cognitive test scores is mainly driven by the positive impact of birth weight on test scores. For PIAT-R Comprehension, we find a significantly negative effect of being born prematurely. We do not find evidence of the importance of HOME scores ages 0 to 1 . Detailed regression results for all tables are available upon request.
} 
Table 8: Non-cognitive Test Scores: BPI and MSD

\begin{tabular}{|c|c|c|c|c|c|c|c|c|}
\hline & \multicolumn{4}{|c|}{$B P I$} & \multicolumn{4}{|c|}{$M S D$} \\
\hline & \multicolumn{2}{|c|}{$\begin{array}{l}\text { 1st assessment } \\
\text { (Ages } 4 \text { to } 5 \text { ) }\end{array}$} & \multicolumn{2}{|c|}{$\begin{array}{l}\text { 2nd assessment } \\
\text { (Ages } 10 \text { to } 11 \text { ) }\end{array}$} & \multicolumn{2}{|c|}{$\begin{array}{l}\text { 1st assessment } \\
\text { (Ages } 0 \text { to } 1 \text { ) }\end{array}$} & \multicolumn{2}{|c|}{$\begin{array}{l}\text { 2nd assessment } \\
\text { (Ages } 2 \text { to } 3 \text { ) }\end{array}$} \\
\hline & (1) & $(2)$ & $(3)$ & $(4)$ & $(5)$ & (6) & $(7)$ & $(8)$ \\
\hline 2nd born & $\begin{array}{l}-0.010 \\
(0.055)\end{array}$ & $\begin{array}{c}0.001 \\
(0.055)\end{array}$ & $\begin{array}{c}-0.024 \\
(0.060)\end{array}$ & $\begin{array}{c}-0.030 \\
(0.061)\end{array}$ & $\begin{array}{l}-0.133 \\
(0.097)\end{array}$ & $\begin{array}{l}-0.101 \\
(0.099)\end{array}$ & $\begin{array}{c}-0.158^{* *} \\
(0.068)\end{array}$ & $\begin{array}{r}-0.154^{* *} \\
(0.067)\end{array}$ \\
\hline 3rd born & $\begin{array}{l}-0.121 \\
(0.099)\end{array}$ & $\begin{array}{l}-0.089 \\
(0.099)\end{array}$ & $\begin{array}{c}-0.253^{* *} \\
(0.101)\end{array}$ & $\begin{array}{c}-0.251^{* *} \\
(0.104)\end{array}$ & $\begin{array}{l}-0.064 \\
(0.171)\end{array}$ & $\begin{array}{l}-0.008 \\
(0.171)\end{array}$ & $\begin{array}{c}-0.286^{* *} \\
(0.118)\end{array}$ & $\begin{array}{r}-0.256^{* *} \\
(0.115)\end{array}$ \\
\hline 4th or higher born & $\begin{array}{l}-0.237 \\
(0.146)\end{array}$ & $\begin{array}{l}-0.185 \\
(0.148)\end{array}$ & $\begin{array}{c}-0.266^{*} \\
(0.152)\end{array}$ & $\begin{array}{l}-0.246 \\
(0.158)\end{array}$ & $\begin{array}{l}-0.269 \\
(0.250)\end{array}$ & $\begin{array}{l}-0.247 \\
(0.244)\end{array}$ & $\begin{array}{c}-0.421^{* *} \\
(0.190)\end{array}$ & $\begin{array}{c}-0.356^{*} \\
(0.185)\end{array}$ \\
\hline F-stat & 5.003 & 3.387 & 3.454 & 2.508 & 3.184 & 3.187 & 4.465 & 3.684 \\
\hline $\mathrm{R}^{2}$ & 0.086 & 0.094 & 0.060 & 0.070 & 0.096 & 0.141 & 0.086 & 0.112 \\
\hline $\mathrm{N}$ & 4622 & 4622 & 4188 & 4188 & 3087 & 3087 & 3977 & 3977 \\
\hline \multicolumn{9}{|c|}{ Controls (F-stat test of joint significance) } \\
\hline prenatal investments & $\mathrm{n} / \mathrm{a}$ & 0.59 & $\mathrm{n} / \mathrm{a}$ & 0.75 & $\mathrm{n} / \mathrm{a}$ & 1.66 & $\mathrm{n} / \mathrm{a}$ & 0.56 \\
\hline birth outcomes & $\mathrm{n} / \mathrm{a}$ & 0.58 & $\mathrm{n} / \mathrm{a}$ & 1.08 & $\mathrm{n} / \mathrm{a}$ & $2.24^{* *}$ & $\mathrm{n} / \mathrm{a}$ & $2.37^{* *}$ \\
\hline postnatal investments & $\mathrm{n} / \mathrm{a}$ & 1.31 & $\mathrm{n} / \mathrm{a}$ & 0.80 & $\mathrm{n} / \mathrm{a}$ & $2.36^{* *}$ & $\mathrm{n} / \mathrm{a}$ & $1.73^{*}$ \\
\hline All controls & $\mathrm{n} / \mathrm{a}$ & 0.85 & $\mathrm{n} / \mathrm{a}$ & 0.80 & $\mathrm{n} / \mathrm{a}$ & $2.29 * * *$ & $\mathrm{n} / \mathrm{a}$ & $1.63^{* *}$ \\
\hline
\end{tabular}

Notes: All regressions are weighted and include family fixed effects. Robust standard errors in parentheses. $*=$ different from zero at the $10 \%$ level. $* *=$ different from zero at the $5 \%$ level. $* * *=$ different from zero at the $1 \%$ level. All assessments have a mean of 0 and a standard deviation of 1. All specifications control for regional dummies, maternal age, gender of the child, age in months at the time of the test and a series of dummies for year of birth. 
Table 9: Non-cognitive Test Scores: SPPC Scholastic and SPPC Global

\begin{tabular}{|c|c|c|c|c|c|c|c|c|}
\hline & \multicolumn{4}{|c|}{ SPPC Scholastic } & \multicolumn{4}{|c|}{ SPPC Global } \\
\hline & \multicolumn{2}{|c|}{$\begin{array}{l}\text { 1st assessment } \\
\text { (Ages } 8 \text { to } 9)\end{array}$} & \multicolumn{2}{|c|}{$\begin{array}{l}\text { 2nd assessment } \\
\text { (Ages } 13 \text { to 14) }\end{array}$} & \multicolumn{2}{|c|}{$\begin{array}{l}\text { 1st assessment } \\
(\text { Ages } 8 \text { to } 9)\end{array}$} & \multicolumn{2}{|c|}{$\begin{array}{l}\text { 2nd assessment } \\
\text { (Ages } 13 \text { to 14) }\end{array}$} \\
\hline & $(1)$ & $(2)$ & $(3)$ & $(4)$ & $(5)$ & $(6)$ & $(7)$ & (8) \\
\hline 2nd born & $\begin{array}{l}-0.169 \\
(0.136)\end{array}$ & $\begin{array}{l}-0.228^{*} \\
(0.136)\end{array}$ & $\begin{array}{c}-0.270 * * * \\
(0.096)\end{array}$ & $\begin{array}{c}-0.310^{* * *} \\
(0.094)\end{array}$ & $\begin{array}{c}-0.333^{* * *} \\
(0.129)\end{array}$ & $\begin{array}{c}-0.326^{* *} \\
(0.136)\end{array}$ & $\begin{array}{c}-0.183^{* *} \\
(0.087)\end{array}$ & $\begin{array}{c}-0.209^{* *} \\
(0.087)\end{array}$ \\
\hline 3rd born & $\begin{array}{l}-0.227 \\
(0.255)\end{array}$ & $\begin{array}{l}-0.305 \\
(0.249)\end{array}$ & $\begin{array}{c}-0.477^{* * *} \\
(0.169)\end{array}$ & $\begin{array}{c}-0.517^{* * *} \\
(0.165)\end{array}$ & $\begin{array}{c}-0.497^{* *} \\
(0.228)\end{array}$ & $\begin{array}{c}-0.501^{* *} \\
(0.237)\end{array}$ & $\begin{array}{c}-0.260^{*} \\
(0.155)\end{array}$ & $\begin{array}{r}-0.306^{*} \\
(0.157)\end{array}$ \\
\hline 4th or higher born & $\begin{array}{l}-0.077 \\
(0.389)\end{array}$ & $\begin{array}{l}-0.202 \\
(0.392)\end{array}$ & $\begin{array}{l}-0.391 \\
(0.260)\end{array}$ & $\begin{array}{r}-0.460^{*} \\
(0.249)\end{array}$ & $\begin{array}{l}-0.593^{*} \\
(0.326)\end{array}$ & $\begin{array}{l}-0.592^{*} \\
(0.341)\end{array}$ & $\begin{array}{l}-0.414^{*} \\
(0.250)\end{array}$ & $\begin{array}{c}-0.511^{* *} \\
(0.251)\end{array}$ \\
\hline F-stat & 1.834 & 1.752 & 1.557 & 1.833 & 1.651 & 1.514 & 1.114 & 1.388 \\
\hline $\mathrm{R}^{2}$ & 0.039 & 0.063 & 0.045 & 0.073 & 0.048 & 0.084 & 0.023 & 0.052 \\
\hline $\mathrm{N}$ & 2508 & 2508 & 2943 & 2943 & 2507 & 2507 & 2943 & 2943 \\
\hline \multicolumn{9}{|c|}{ Controls (F-stat test of joint significance) } \\
\hline prenatal investments & $\mathrm{n} / \mathrm{a}$ & 0.91 & $\mathrm{n} / \mathrm{a}$ & 0.57 & $\mathrm{n} / \mathrm{a}$ & 0.96 & $\mathrm{n} / \mathrm{a}$ & 1.69 \\
\hline birth outcomes & $\mathrm{n} / \mathrm{a}$ & 0.55 & $\mathrm{n} / \mathrm{a}$ & 1.66 & $\mathrm{n} / \mathrm{a}$ & 1.55 & $\mathrm{n} / \mathrm{a}$ & $2.10^{* *}$ \\
\hline postnatal investments & $\mathrm{n} / \mathrm{a}$ & 0.96 & $\mathrm{n} / \mathrm{a}$ & $1.77^{*}$ & $\mathrm{n} / \mathrm{a}$ & 1.65 & $\mathrm{n} / \mathrm{a}$ & 0.80 \\
\hline All controls & $\mathrm{n} / \mathrm{a}$ & 0.99 & $\mathrm{n} / \mathrm{a}$ & $1.68^{* *}$ & $\mathrm{n} / \mathrm{a}$ & 1.29 & $\mathrm{n} / \mathrm{a}$ & $1.46^{*}$ \\
\hline
\end{tabular}

Notes: All regressions are weighted and include family fixed effects. Robust standard errors in parentheses. $*=$ different from zero at the $10 \%$ level. $* *=$ different from zero at the $5 \%$ level. $* * *=$ different from zero at the $1 \%$ level. All assessments have a mean of 0 and a standard deviation of 1. All specifications control for regional dummies, maternal age, gender of the child, age in months at the time of the test and a series of dummies for year of birth. 
the motor and social development (MSD) assessment at very early ages (Table 8 , columns 5 and 7). In the second assessment, for which the results are more precise, a second-born child scores approximately 0.15 standard deviations lower on the MSD than the first-born, with the third and the fourth (and higher) children scoring 0.3 to 0.4 standard deviations lower. In Table 9, we also find that there is a strong negative birth order effect on both scholastic and global measures of self-worth (SPPC), yet slightly different trends for the two measures. The negative effects of higher birth order appear to be reinforced with age for the scholastic SPPC, although the estimates in the first assessment lack precision, ranging from a difference of 0.17 to 0.27 standard deviations between the second- and the firstborn. However, the global measures of self-worth reveal, if anything, evidence of an opposite trend: a first-born scores 0.33 standard deviations better than the second-born at ages 8 to 9 but only 0.18 standard deviations better at ages 13 to 14 . The trends are similar for higher-birth order children. However, for both scales of SPPC, there exists a significant and large negative relationship between birth order and the children's self-reported sense of selfworth. Psychological literature has found that there is a statistically significant correlation between measures of self-worth as a teenager and educational attainment (Bachman and O'Malley 1977). Thus, differences in the children's view of self and confidence may be a channel through which early childhood environment can contribute to birth order differences in adult outcomes.

To investigate whether these significant birth order effects found in the BPI, MSD, and SPPC assessments are robust to accounting for differences in early childhood conditions, we add these controls in the even columns of Tables 8 and 9 and report the F-statistics for the test of joint significance of each subset of added controls. Again, as in the case of cognitive tests, differences in early investments and conditions, including HOME scores, fail to account for the large observed birth order effect on non-cognitive tests. In fact, the inclusion of early childhood conditions appear to increase the size of birth order effects on SPPC scores 27

\footnotetext{
${ }^{27}$ Again, detailed regression results from Tables 8 and 9 are available upon request. The significant effect of birth outcomes on cognitive test scores is again mainly driven by negative impact of being overweight or
} 
In summary, although we find significant differences in pre/postnatal investments, birth outcomes, and home environment across children of different birth order, these early childhood conditions fail to explain the negative relationship between birth order and measures of cognitive and non-cognitive outcomes in our data. These results are robust to including controls for family income and welfare payments and mother's employment status as well as the presence of the birth father in the household at the time of the assessment. Further, restricting the sample to children with scores from both the first and the second assessments do not alter our main results.28

\subsection{Differences in Educational Attainment by Birth Order: The Role of Early Investments and Early Test Scores}

To place our results in the context of existing literature, we now turn to investigating the presence of and the potential sources of birth order effects in educational attainment, an outcome that has been the focus of most previous studies on birth order. Table 10 presents the results for years of education completed and high school graduation. College attendance provides similar results as high school graduation, but the estimates are too imprecise to warrant further investigation. We measure educational attainment in the latest survey year 2010 to include as many observations as possible of individuals with completed education. All specifications include cohort controls to account for the obvious impact of age on years of completed education.

First, we find evidence of birth order effects in educational attainment, similar to the findings in the previous literature. Second-born children, on average, have about 0.5 less years of education than first-borns, and this difference increases to 0.8 years for third children and to more than a year for fourth and higher-ordered children (Table 10, column 1) ${ }^{29}$ The size of

underweight at birth on test scores. We find some evidence of a positive impact of cognitive and emotional home environment on MSD scores at 2nd assessment.

${ }^{28}$ The sample restriction yields similar point estimates, however, due to the decreased sample size, the estimates are not as precise and we lose some statistical significance.

${ }^{29}$ The results below are robust to a more restrictive specification in which we restrict the sample to those 
Table 10: Birth order and Educational Attainment

\begin{tabular}{|c|c|c|c|c|c|}
\hline & \multicolumn{5}{|c|}{ Years of Education } \\
\hline & (1) & $(2)$ & $(3)$ & $(4)$ & $(5)$ \\
\hline 2nd born & $\begin{array}{c}-0.460 * * * \\
(0.120)\end{array}$ & $\begin{array}{c}-0.411^{* * *} \\
(0.116)\end{array}$ & $\begin{array}{c}-0.267^{*} \\
(0.137)\end{array}$ & $\begin{array}{l}-0.264 \\
(0.229)\end{array}$ & $\begin{array}{l}-0.231 \\
(0.224)\end{array}$ \\
\hline 3rd born & $\begin{array}{c}-0.789^{* * *} \\
(0.222)\end{array}$ & $\begin{array}{c}-0.728^{* * *} \\
(0.217)\end{array}$ & $\begin{array}{c}-0.502^{* *} \\
(0.252)\end{array}$ & $\begin{array}{l}-0.140 \\
(0.431)\end{array}$ & $\begin{array}{l}-0.509 \\
(0.409)\end{array}$ \\
\hline 4th or higher born & $\begin{array}{c}-1.057^{* * *} \\
(0.388)\end{array}$ & $\begin{array}{c}-1.003^{* * *} \\
(0.372)\end{array}$ & $\begin{array}{c}-0.637^{*} \\
(0.345)\end{array}$ & $\begin{array}{l}-0.758 \\
(0.622)\end{array}$ & $\begin{array}{c}-1.230^{* *} \\
(0.589)\end{array}$ \\
\hline F-stat & 28.872 & 17.415 & 21.116 & 14.368 & 12.388 \\
\hline $\mathrm{R}^{2}$ & 0.327 & 0.339 & 0.362 & 0.536 & 0.621 \\
\hline $\mathrm{N}$ & 4496 & 4496 & 3075 & 1612 & 1458 \\
\hline \multicolumn{6}{|c|}{ Controls (F-test for joint significance) } \\
\hline Early investments & $\mathrm{n} / \mathrm{a}$ & $1.71^{* *}$ & $\mathrm{n} / \mathrm{a}$ & $\mathrm{n} / \mathrm{a}$ & $3.43^{* * *}$ \\
\hline Cognitive scores & $\mathrm{n} / \mathrm{a}$ & $\mathrm{n} / \mathrm{a}$ & $11.11^{* * *}$ & $\mathrm{n} / \mathrm{a}$ & $2.01^{*}$ \\
\hline \multirow[t]{3}{*}{ Non-cognitive scores } & $\mathrm{n} / \mathrm{a}$ & $\mathrm{n} / \mathrm{a}$ & $\mathrm{n} / \mathrm{a}$ & $5.95 * * *$ & $4.88^{* * *}$ \\
\hline & & High & chool grad & & \\
\hline & (1) & $(2)$ & (3) & $(4)$ & $(5)$ \\
\hline \multirow[t]{2}{*}{ 2nd born } & $-0.030^{* *}$ & $-0.028^{*}$ & $-0.025^{*}$ & -0.005 & 0.006 \\
\hline & $(0.015)$ & $(0.016)$ & $(0.015)$ & $(0.015)$ & $(0.017)$ \\
\hline \multirow[t]{2}{*}{ 3rd born } & $-0.064^{* *}$ & $-0.059 * *$ & $-0.053^{*}$ & 0.013 & 0.039 \\
\hline & $(0.030)$ & $(0.030)$ & $(0.031)$ & $(0.025)$ & $(0.039)$ \\
\hline \multirow[t]{2}{*}{ 4th or higher born } & -0.062 & -0.057 & -0.066 & 0.014 & 0.055 \\
\hline & $(0.045)$ & $(0.047)$ & $(0.044)$ & $(0.034)$ & $(0.047)$ \\
\hline $\mathrm{R}^{2}$ & 0.020 & 0.023 & 0.029 & 0.050 & 0.261 \\
\hline $\mathrm{N}$ & 4218 & 4218 & 2841 & 1391 & 1252 \\
\hline \multicolumn{6}{|c|}{ Controls (F-test for joint significance) } \\
\hline Early investments & $\mathrm{n} / \mathrm{a}$ & 0.58 & $\mathrm{n} / \mathrm{a}$ & $\mathrm{n} / \mathrm{a}$ & 0.60 \\
\hline Cognitive scores & $\mathrm{n} / \mathrm{a}$ & $\mathrm{n} / \mathrm{a}$ & $2.97^{* *}$ & $\mathrm{n} / \mathrm{a}$ & 0.71 \\
\hline Non-cognitive scores & $\mathrm{n} / \mathrm{a}$ & $\mathrm{n} / \mathrm{a}$ & $\mathrm{n} / \mathrm{a}$ & 0.58 & 0.34 \\
\hline
\end{tabular}

Notes: All regressions are weighted and include family fixed effects. Robust standard errors in parentheses. ${ }^{*}=$ different from zero at the $10 \%$ level. ${ }^{* *}=$ different from zero at the $5 \%$ level. ${ }^{* * *}=$ different from zero at the $1 \%$ level. All specifications control for regional dummies, maternal age, gender, multiple birth and a series of dummies for year of birth. Education attainment is measured in 2010, and high school graduation is defined for children over 20. Cognitive and non-cognitive scores correspond to the second assessment.

who are at least 20 years old. 
these birth effects on educational attainment is comparable to the finding in Kantarevic and Mechoulan (2006) in which the first-born tend to receive 0.4 to 0.9 years of more education compared to higher-ordered children.

The bottom panel of Table 10 presents the results for high school completion for children who were at least 20 years old by 2010. We find that higher order children are between 3 and 6 percentage points less likely to graduate from high school than the first-born.

\subsubsection{The Role of Early Investments}

Column 2 of Table 10 shows the robustness of the birth order effect in educational attainment when controlling for pre/postnatal investment and birth outcomes. Similar to cognitive and non-cognitive tests, differences in early investments do not appear to drive the birth order effect in educational attainment. Although better early investments (particularly in the case of postnatal investments, such as breastfeeding or HOME scores) are associated with higher educational attainment even within the same family, our results show that these disparities are not the main driving forces behind the observed birth order effect on educational attainment.

\subsubsection{Early Test Scores and Years of Education Completed}

In Tables 6 through 9, we observed strong birth order effects in both cognitive and noncognitive outcomes in the children's early years. Columns 3 and 4 of Table 10 test whether these observed differences in cognitive and non-cognitive outcomes early in life can explain differences in educational attainment in adulthood 30 We choose to focus on test scores from the second assessment, because differences in scores by birth order appear most strongly in early adolescence in our data. Furthermore, controlling for the first assessments decreases our sample size by a significantly larger number than with the second assessments, and we

\footnotetext{
${ }^{30}$ The results are robust to restricting the sample to children reporting early investment and both cognitive and non-cognitive scores at age of second assessment.
} 
are able to retain a much larger statistical power by focusing on the second. ${ }^{31}$

As shown in column (3), cognitive test scores have, as expected, some predictive power in explaining differences in years of education completed, especially PIAT-M and PIAT-R Recognition scores. Additionally, cognitive scores at adolescence appear to partially explain the birth order effect, reducing the magnitude by about 35 percent ${ }^{32}$ We obtain similar results when we control for non-cognitive test scores (column 4), mainly driven by measures of self-worth and behavior problems. Test for the joint significance of the non-cognitive scores reveal that early non-cognitive outcomes are significant predictors of years of education completed. Non-cognitive scores are also able to partially explain the birth order effects in educational attainment, reducing the size of the birth order effects by similar magnitudes as the addition of cognitive test controls, at least for the second-born. However, the addition of all non-cognitive as controls substantially reduces our sample size, and the birth order effects lose their statistical significance.

In order to shed a greater light on the underlying channels behind the birth order effects in educational attainment, we run a "horse race" in column (5) between the three potential explanations explored in Table 10. While the estimates lose their significance due to the large drop in sample size, the point estimates remain very similar to columns (3) and (4), with the birth order effects being reduced by at least 0.2 years of education for the second- and third-born children, while higher-ordered children still showing significantly lower educational attainment when compared to the first-born.

The reduction of the birth order effects in educational attainment when controlling for cognitive test scores is not reflected in the share of children that completed high school (bottom panel of Table 10, columns 3 to 5). While cognitive test scores, in particular PIAT-

\footnotetext{
${ }^{31}$ Using the cognitive scores from the first assessments reduces our sample size from 4496 in column (2) to 912 in column (3), 489 in column (4), and a mere 112 in column (5). Controlling for test scores from the first assessments despite this dramatic reduction in sample size reveals that the size of the birth order effects on years of education completed is robust to the addition of these controls. Early cognitive assessments do not have much explanatory power for years of education while non-cognitive scores, especially SPPC, have some predictive power.

${ }^{32}$ However, we cannot reject the null that the size of the birth order effects are equal between columns (2) and (3) or between columns (2) and (4).
} 
$\mathrm{R}$ Recognition scores, are able to predict variations in high school graduation, the trend by birth order is robust to their inclusion. Controlling for non-cognitive scores reduces the point estimates, but the lack of precision in the estimates prevents any further interpretation of the results 33

\section{Conclusion}

Our paper makes a number of key contributions to the birth order literature. First, motivated by the rich literature on the significance of in utero and early childhood environment and later outcomes, we consider differences in parental investment from the moment of conception to the earliest years of the child's life as potential explanations of birth order effects in education outcomes. We examine a wide range of prenatal and postnatal investments, as well as birth outcomes, in an attempt to pinpoint the earliest start of birth order differences in achievement. We find that some measures of maternal investments before and after birth are negatively correlated with increasing birth order. For example, women are less likely to reduce their smoking during pregnancy and are less likely to breastfeed children of higher order. However, while higher order children are less likely to be premature, they are also less likely to be born underweight and more likely to be born overweight. We also find strong and significant differences in the home environment for children ages 0 to 1 across birth order. Compared to the first-born, children of higher birth order face lower cognitive stimulation/resources and emotional support from their parents.

Second, to our knowledge, this is the first attempt to test whether there exist birth order effects across many types of early cognitive and non-cognitive test scores. We observe significant differences by the order of birth in several cognitive and non-cognitive tests. Higher order children perform worse on PIAT-Reading and PPVT tests and exhibit significantly lower measures of self-worth, both scholastically and globally, and motor and social devel-

\footnotetext{
${ }^{33}$ While the sample size is reduced by requiring children to have reached age 20 in 2010 to be included in this sample, variation in high school completion within family is also lower.
} 
opment at early ages.

Despite our finding that there exist some significant differences in pre/postnatal investments across children of different birth order, including the home environment, we find that the observed differences in cognitive and non-cognitive scores by birth order are robust in both their magnitude and significance to accounting for these systematic variations in early childhood conditions. We find a strong negative relationship between birth order and educational attainment for the first time in the CNLSY79 cohorts. Even in this very young cohort, we find birth order effects that are of similar magnitudes found in previous studies, suggesting that these effects have not diminished over time. As in the case of cognitive and non-cognitive outcomes, while breastfeeding patterns and early home environment have some predictive power for years of education completed, we find that variations in early childhood conditions do not diminish the size of the birth order effects in educational attainment.

Additionally, we find that early cognitive and non-cognitive test scores are able to explain a significant portion of the birth order effects. The inclusion of these test scores from adolescence reduces the size of the birth order effects by about 35 percent. Test scores, however, are of course endogenous to the child's mental, physical, and social development, and we are unable to draw much causal inferences from these associations. This difficulty is especially complicated by our finding that our measures of pre/postnatal investments and early home environment are unable to explain the birth order effects in cognitive and non-cognitive test scores both in the child's early ages and adolescence.

We believe that the results from this paper suggest several possible interpretations that can guide future research. One, birth order effects on educational outcomes are indeed not determined by biological differences or variations in early childhood environments; two, its effects are latent until later in adulthood possibly through the late onset of health effects; or three, common measures of prenatal and early childhood conditions fail to adequately capture critical differences in early health and home environment conditions within a family. Greater future inquiries into these various interpretations is required to assess the relative 
strengths of these hypotheses.

Finally, in light of the strong relationship between measures of self-worth at adolescence and educational attainment as well as the significant relationship between early home environment and the SPPC scores, we surmise that a magnification of difference in children's early family investments and environments through the early years on the children's view of self-worth, motivation, and parent-imposed expectations may be a potential channel through birth order effects in adult outcomes may arise. In that vein, a recent study examining the relationship between adolescent depression and labor market outcomes using a school-based, longitudinal study on health-related behaviors in the U.S. find that individuals with depressive symptoms as an adolescent experienced 5 percentage point reductions in labor force attachment and approximately 20\% reduction in adult earnings (Fletcher 2012). Further exploring the origins of birth order differences in the children's view of self and parental expectations using rigorous statistical techniques may shed some light on the unexplained relationship between higher birth order and lower achievement in adolescence and adulthood. 


\section{References}

Almond, Douglas and Janet Currie (2010) "Human capital development before age five," NBER Working Papers 15827, National Bureau of Economic Research, Inc.

Angrist, Joshua D. and William N. Evans (1998) "Children and Their Parents' Labor Supply: Evidence from Exogenous Variation in Family Size," The American Economic Review, Vol. 88, No. 3, pp. 450-477.

Bachman, Jerald G. and Patrick M. O’Malley (1977) "Self-esteem in young men: A longitudinal analysis of the impact of educational and occupational attainment.," Journal of Personality and Social Psychology, Vol. 35, No. 6, pp. 365-380.

Baker, Paula C., Canada K. Keck, Frank L. Mott, and Stephen V. Quinlan (1993) The NLSY Child Handbook 1993: A Guide and Resource Document for the NLSY of Youth - Child Data: Columbus, OH: Center for Human Resource Research, The Ohio State University.

Barker, David J. (1990) "The fetal and infant origins of adult disease.," British Medical Journal, Vol. 301, No. 6761, p. 1111.

Behrman, Jere R. and Paul Taubman (1986) "Birth order, schooling, and earnings," Journal of Labor Economics, Vol. 4, No. 3, pp. 121-145.

Belfield, C.R. and I.R. Kelly (2010) "The Benefits of Breastfeeding Across the Early Years of Childhood," NBER Working Papers 16496, National Bureau of Economic Research.

Birdsall, N. (1991) "Birth order effects and time allocation.," Research in population economics, Vol. 7, p. 191.

Black, Sandra E., Paul J. Devereux, and Kjell G. Salvanes (2005) "The More the Merrier? The Effect of Family Size and Birth Order on Children's Education," Quarterly Journal of Economics, Vol. 120, No. 2, pp. 669-700. 
(2007a) "From the Cradle to the Labor Market? The Effect of Birth Weight on Adult Outcomes*," The Quarterly Journal of Economics, Vol. 122, No. 1, pp. 409-439.

- (2007b) "Older and wiser? Birth order and IQ of young men," NBER Working Paper \#1323\%.

Blake, J. (1989) Family size and achievement, Vol. 3: University of California Press.

Booth, Alison L. and Hiau Joo Kee (2009) "Birth order matters: the effect of family size and birth order on educational attainment," Journal of Population Economics, Vol. 22, No. 2, pp. 367-397.

Carlson, M.J. and M.E. Corcoran (2001) "Family structure and children's behavioral and cognitive outcomes," Journal of Marriage and Family, Vol. 63, No. 3, pp. 779-792.

CDC (2001) "Women and smoking: a report of the Surgeon General,"Technical report, US Department of Health and Human Services, Atlanta, GA.

(2004) "The health consequences of smoking: a report of the Surgeon General,'Technical report, US Department of Health and Human Services, Atlanta, GA.

Chung, M., G. Raman, P. Chew, N. Magula, T. Trikalinos, and J. Lau (2007) "Breastfeeding and maternal and infant health outcomes in developed countries," Evid Technol Asses (Full Rep), Vol. 153, pp. 1-186.

Cunha, Glavio and James J. Heckman (2007) "The economics of human development: The technology of skill formation," The American economic review, Vol. 97, No. 2, pp. $31-47$.

Currie, Janet and Jeffrey Grogger (2002) "Medicaid expansions and welfare contractions: offsetting effects on prenatal care and infant health?" Journal of Health Economics, Vol. 21, No. 2, pp. 313-335. 
Dominguez-Rojas, V., J. R. de Juanes-Pardo, P. Astasio-Arbiza, P. Ortega-Molina, and E. Gordillo-Florencio (1994) "Spontaneous abortion in a hospital population: Are tobacco and coffee intake risk factors?" European Journal of Epidemiology, Vol. 10, pp. 665-668. 10.1007/BF01719278.

Ejrnæs, M. and C.C. Pörtner (2004) "Birth order and the intrahousehold allocation of time and education," Review of Economics and Statistics, Vol. 86, No. 4, pp. 1008-1019.

Eriksson, M., H. Wedel, M.A. Wallander, I. Krakau, J. Hugosson, S. Carlsson, and K. Svärdsudd (2007) "The impact of birth weight on prostate cancer incidence and mortality in a population-based study of men born in 1913 and followed up from 50 to 85 years of age," The Prostate, Vol. 67, No. 11, pp. 1247-1254.

Fingerhut, L A, J C Kleinman, and J S Kendrick (1990) "Smoking before, during, and after pregnancy.," Am J Public Health, Vol. 80, No. 5, pp. 541-544.

Fletcher, Jason M. (2012) "Adolescent Depression and Adult Labor Market Outcomes," Working Paper 18216, National Bureau of Economic Research.

Fryer, R.G. and S.D. Levitt (2004) "Understanding the black-white test score gap in the first two years of school," Review of Economics and Statistics, Vol. 86, No. 2, pp. 447-464.

Gillman, M.W., S. Rifas-Shiman, C.S. Berkey, A.E. Field, and G.A. Colditz (2003) "Maternal gestational diabetes, birth weight, and adolescent obesity," Pediatrics, Vol. 111, No. 3, pp. e221-e226.

Gluckman, Peter D. and Mark Hanson (2005) The fetal matrix: evolution, development, and disease: Cambridge University Press.

Hanushek, E.A. (1992) "The Trade-off between Child Quantity and Quality," The Journal of Political Economy, Vol. 100, No. 1, pp. 84-117. 
Harder, T., A. Plagemann, and A. Harder (2008) "Birth weight and subsequent risk of childhood primary brain tumors: a meta-analysis," American journal of epidemiology, Vol. 168, No. 4, pp. 366-373.

Heckman, J.J., J. Stixrud, and S. Urzua (2006) "The effects of cognitive and noncognitive abilities on labor market outcomes and social behavior,'Technical report, National Bureau of Economic Research \#12006.

Heckman, James J. (2007) "The economics, technology, and neuroscience of human capability formation," Proceedings of the National Academy of Sciences, Vol. 104, No. 33, p. 13250.

Heckman, James J. and Dimitriy V. Masterov (2007) "The productivity argument for investing in young children," Applied Economic Perspectives and Policy, Vol. 29, No. 3, p. 446.

Heiland, Frank (2009) "Does the birth order affect the cognitive development of a child?" Applied Economics, Vol. 41, No. 14, pp. 1799-1818.

Hjalgrim, L.L., T. Westergaard, K. Rostgaard, K. Schmiegelow, M. Melbye, H. Hjalgrim, and E.A. Engels (2003) "Birth weight as a risk factor for childhood leukemia: a metaanalysis of 18 epidemiologic studies," American journal of epidemiology, Vol. 158, No. 8, pp. 724-735.

Horwood, L.John and David M. Fergusson (1998) "Breastfeeding and later cognitive and academic outcomes," Pediatrics, Vol. 101, No. 1, p. e9.

Iacovou, Maria (2001) "Family composition and children's educational outcomes," ISER Working Paper Series.

Kantarevic, Jasmin and Stéphane Mechoulan (2006) "Birth Order, Educational Attainment, and Earnings," Journal of Human Resources, Vol. 41, No. 4, pp. 755-777. 
Kessler, Daniel (1991) "Birth order, family size, and achievement: Family structure and wage determination," Journal of Labor Economics, pp. 413-426.

Knudsen, Eric I., James J. Heckman, Judy L. Cameron, and Jack P. Shonkoff (2006) "Economic, neurobiological, and behavioral perspectives on building America's future workforce," Proceedings of the National Academy of Sciences, Vol. 103, No. 27, p. 10155.

Lang, Kevin and Carlos E. Sepulveda (2007) "The Black-White Test Score Differential," Boston University Working Paper.

Leong, N.M., L.I. Mignone, P.A. Newcomb, L. Titus-Ernstoff, J.A. Baron, A. TrenthamDietz, M.J. Stampfer, W.C. Willett, and K.M. Egan (2003) "Early life risk factors in cancer: the relation of birth weight to adult obesity," International journal of cancer, Vol. 103, No. 6, pp. 789-791.

Lewis, CT, TJ Mathews, and RL Heuser (1996) "Prenatal care in the United States, 198094.," Vital and health statistics. Series 21, Data on natality, marriage, and divorce, No. 54 , p. 1.

MacArthur, C and EG Knox (1988) "Smoking in pregnancy: effects of stopping at different stages.," Br J Obstet Gynaecol, Vol. 95, No. 6, pp. 551-555.

Monfardini, Chiara and Sarah Grace See (2011) "Birth Order and Child Outcomes: Does Maternal Quality Time Matter?" Unpublished Manuscript.

Oddy, W.H., G.E. Kendall, E. Blair, N.H. De Klerk, F.J. Stanley, L.I. Landau, S. Silburn, and S. Zubrick (2003) "Breast feeding and cognitive development in childhood: a prospective birth cohort study," Paediatric and perinatal epidemiology, Vol. 17, No. 1, pp. 81-90.

Parish, W.L. and R.J. Willis (1993) "Daughters, education, and family budgets Taiwan experiences," Journal of Human Resources, pp. 863-898. 
Parsons, TJ, C. Power, S. Logan, CD Summerbell et al. (1999) "Childhood predictors of adult obesity: a systematic review.," International journal of obesity and related metabolic disorders: journal of the International Association for the Study of Obesity, Vol. 23, p. S1.

Peterson, James L. and Nicholas Zill (1986) "Marital disruption, parent-child relationships, and behavior problems in children," Journal of Marriage and the Family, pp. 295-307.

Pietiläinen, K.H., J. Kaprio, M. Räsänen, T. Winter, A. Rissanen, and R.J. Rose (2001) "Tracking of body size from birth to late adolescence: contributions of birth length, birth weight, duration of gestation, parents' body size, and twinship," American Journal of Epidemiology, Vol. 154, No. 1, pp. 21-29.

Price, Joseph (2008) "Parent-Child Quality Time," Journal of Human Resources, Vol. 43, No. 1, pp. 240-265.

Remes, ST, SP Patel, A.L. Hartikainen, M.R. Jarvelin, and J. Pekkanen (2008) "High birth weight, asthma and atopy at the age of 16 yr," Pediatric Allergy and Immunology, Vol. 19, No. 6, pp. 541-543.

Rodgers, Joseph Lee, H. Harrington Cleveland, Edwin van den Oord, and David C. Rowe (2000) "Resolving the debate over birth order, family size, and intelligence.," American Psychologist, Vol. 55, No. 6, p. 599.

Smith-Conway, Karen and Partha Deb (2005) Journal of Health Economics, Vol. 24, No. 3, pp. 489-513.

Strauss, R.S. and J. Knight (1999) "Influence of the home environment on the development of obesity in children," Pediatrics, Vol. 103, No. 6, pp. e85-e85. 
Todd, P.E. and K.I. Wolpin (2007) "The production of cognitive achievement in children: Home, school, and racial test score gaps," Journal of Human capital, Vol. 1, No. 1, pp. $91-136$.

Wei, J.N., H.Y. Li, F.C. Sung, C.C. Lin, C.C. Chiang, C.Y. Li, and L.M. Chuang (2007) "Birth Weight Correlates Differently with Cardiovascular Risk Factors in Youth\&ast," Obesity, Vol. 15, No. 6, pp. 1609-1616.

Zajonc, R.B. (1976) "Family configuration and intelligence: Variations in scholastic aptitude scores parallel trends in family size and the spacing of children.," Science. 